(Aus der Universitäts-Augenklinik Basel.)

\title{
Weitere Ergebnisse der Spaltlampenmikroskopie des vordern Bulbusabschnittes.
}

\section{Abschnitt Cataracta traumatica und Cataracta complicata ${ }^{1}$ ). Mit Rückschlüssen auf die Entwicklung und den Aufbau der mensch- lichen Linse.}

Von

Alfred Vogt.

Mit 50 Textabbillungen.

Weiterer Beitrag zur Vossiusschen Ringauflagerung ( $\mathrm{Ab} b .3$ ).

Die Vossiussche Ringauflagerung galt bisher als ausschlieBliche Kontusionsfolge. Hesse bestreitet neuerdings diese Ätiologie. Nach ihm entsteht der Ring durch Ablagerung von Blut aus der Vorderkammer und hat daher mit der Kontusion nichts zu tun. Bedingung zu ihrer Entstehung ist nach Hesse einzig die Vorderkammerblutung.

Hesse setzt sich mit dieser seiner Behauptung in Gegensatz zu allen anderen bisherigen Beobachtern (es sind etwa 25), welche zum Teil über eine Reihe von Fällen verfügen: In allen diesen Fällen war der Ringbildung ein plötzliches Trauma vorhergegangen, sei es eine Kontusion, sei es eine Perforation. Niemals war sie nach Vorderkammerblutung nicht traumatischer Art beobachtet.

Aber Hesse ist es nun kürzlich gelungen, durch einen eigenen Fall seine Hypothese zu stützen. Fr sah nämlich eine Ringtrübung im Verlaufe einer Glaskörperblutung, die im Anschlusse an zweimalige Punktion des Glaskörpers aufgetreten war. Das Blut war in die Vorderkammer gelangt und führte auf der Linse zu einer Ringauflagerung. Die Beweisführung in dieser Hesseschen Beobachtung erscheint mir allerdings nicht ganz schlüssig. Hesse unterläßt nämlich eine genauere Beschreibung dieses neuartigen, allen bisherigen Beobachtungen widersprechenden Falles. Weder erfahren wir etwas über das mikroskopische Aussehen, die Breite, das Lumen des Ringes, noch über den Verlauf. Eine hinreichende Begründung in Form einer genauen Beschreibung würde man aber doch bei einer prinzipiell so neuen Beobachtung erwarten dürfen.

1) Die Abbildungen sind auf $4 / 5$ verkleinert. 
Von vornherein erscheint es mir durchaus nicht so feststehend, daß die erwähnte Hessesche Ringbildung tatsächlich eine Tossiussche Ringtrübung war. Das Hessesche Auge ist zweimal punktiert worden. Gewissen operativen Bulbuseröffnungen, z. B. der Trepanation, können aber nach unseren Beobachtungen entweder bald oder erst nach Tagen und Wochen gröbere, oder zartere Ringauflagerungen auf der Vorderkapsel folgen - ohne daß iritische Erscheinungen nachweisbar sind - welche Auflagerungen aus Exsudat, Pigmentkörnchen und Klümpchen bestehen und unseres Erachtens Anlaß zu Verwechslung mit Vossiusscher Ringauflagerung geben könnten. Im Gegensatz zu letzterer pflegen solche Auflagerungen durch viele Monate und länger bestehen zu bleiben.

Aber auch sehr schleichende Formen von sog. endogener Iridocyclitis können vereinzelt ganz ähnliche Ringauflagerungen erzeugen.

$A b b .2$ gibt den nasalen Abschnitt eines solchen Ringes $R$ bei 24 facher Vergrößerung wieder, wie er bei der 50 jährigen Frau K., die seit mehreren Jahren

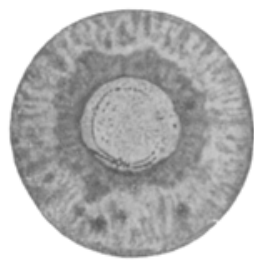

Abb. 1.

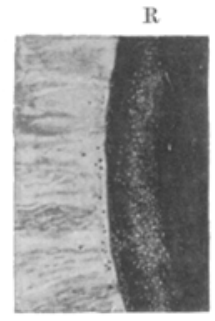

Abb. 2*

an schleichender Uveitis leidet, 1/2 Jahr nach dem Rückfalle beobachtet wurde. Abb. 1 zeigt den Ring bei Durchleuchtung mit Lupenspiegel. Eine solche Auflagerung kann in seltenen Fällen ihrer ganzen Ausdehnung nach, häufiger wenigstens stellenweise, das Bild der Vossiusschen Ringauflagerung vortäuschen. Gröbere Pigmentpartikel, manohmal auch Exsudatreste, können fehlen oder nur schwer nachweisbar sein. (Von den von mir beobachteten einwandfreien Fällen von Vossiusscher Ringauflagerung unterscheidet sich die Ringbildung der Abb. 1 vor allem durch die geringere Ringbreite [ca. 0,1 statt $0,2 \mathrm{~mm}$ ] und das nicht ganz gleichmäBige, eher etwas gröbere Korn, sowie endich durch einzelne Auflagerungen peripher des Ringes.)

Ich möchte also einstweilen das Vorkommen einer nicht traumatischen Vossiusschen Ringauflagerung, im Gegensatz zu Hesse, nicht als erwiesen betrachten. Dies umso weniger, als uns ein Überblick über die bisherigen Fälle lehrt, daß die Vossiussche Auflagerung sehr wahrscheintich im Momente des Traumas zustande kommt, und als sich, wie wir sehen werden, zeigen läßt, daß die Hessesche Hypothese mit den tatsächlichen Befunden nicht im Einklang steht.

Da für Hesse das Trauma nicht conditio ist, erklärt er sich die Tat 
sache des Freibleibens der peripheren Linsenkapsel durch eine zusammenscheuernde Wirkung der Iris. Durch das Pupillenspiel werde das Blut auf der Vorderkapsel zu einer Art Ring zusammengeschoben. Diese physikalische Vorstellung erscheint nicht haltbar.

Erstens werden die Blutkörperchen, wenn sie überhaupt ,zusammenscheuerbar" sind, also sich von ihrer Unterlage loswischen lassen, in das Kammerwasser gelangen. Von einer Ringbildung durch Zusammenscheuerung kann also keine Rede sein. Eine solche könnte nur dann zustande kommen, wenn man die weitere - doch gewiß nicht ernst. zu nehmende - Annahme machte, daßs die Pünktchen hinterher wieder, nach ihrer Losscheverung, aus irgendeinem unbekannten Grunde sich anlegten und zwar gerade in der gewünschten Ringform! Aber auch dann wäre immer noch nicht erklärt, warum dieser Vorgang in allen Fällen gerade nur zur Zeit des Traumas - und später nicht mehr! - stattände. Ein Überblick über die Beobachtungen zeigt, daß die Ringauflagerung schon in den allerfrühest beobachteten Stadien $d a$ ist und zwar schon in kompleter, endgültiger Form! Ja daB sie im Falle Caspar (1909) schon unter einem gleichzeitig vorhandenen Blutkoagulum, das sich nach dem Trauma gebildet hatte, bestand, also mit diesem nichts zu tun hatte. Niemals wurde beobachtet, daß etwa die Ringtrübung erst im Laufe der dem Trauma folgenden Stunden oder Tage sich gebildet oder auch nur zugenommen hätte. Eine solche Bildung oder doch Zunahme müßte man aber bei der von Hesse angenommenen Zusammenscheuerung, bzw. bei der ebenfalls von Hesse behaupteten bloßen Anlagerung des Blutes aus der Vorderkammer erwarten, da sich doch Blut nach allen schweren Kontusionen längere Zeit, häufig mehrere Tage lang im Vorderkammerwasser in reichlicher Menge nachweisen läßt. Im Gegenteil, übereinstimmend berichten die Autoren, daß der Ring am ersten Tage der Beobachtung am kräftigsten war. Wenn Lupenspiegel und Spaltlampenmikroskop herangezogen wurden, sah man in den folgenden Stunden und Tagen die Auflagerung sukzessive abnehmen und schwinden. Wer den Ring, wie ihn das Spaltlampenmilkroskop zeigt, sorgfältig durch Zeichnung festhält und dabei die verschiedenen UnregelmäBigkeiten, Einschnitte, leeren Stellen exakt skizziert, die Ringbreite der verschiedenen Partien mißt und durch Tage und Wochen immer wieder kontrolliert, wird nicht, auch wenn die Vorderkammer noch tagelang Blut enthält, eine Apposition feststellen können. Er wird vielmehr von Beginn an die Pünktchen solid auf der Kapsel kleben sehen, nirgends sieht er eine Häufung oder Konglobierung, oder gar, wie es doch nach Hesses Annahme denkbar sein müßte, eine neue Anlagerung. Der definitive fertige Zustand ist also durch das Trauma gegeben. Auch der Um. stand, daß bis jetzt eine zwei- oder mehrfache Ringbildung kein ein- 
ziges Mal beobachtet wurde, was (bei Hesses Annahme) in allen jenen Fällen im Bereiche der Möglichkeit läge, in denen die Pupille post trauma durch Sphineterrisse dilatiert gefunden wird, oder in denen wir sie mit Cocain oder Homatropin zu Untersuchungszwecken erweitern, spricht in hohem Maße gegen nachträgliche Ablagerung aus dem Kammerwasser. Stets ist ein Ring vorhanden, eben der post trauma gefundene. Auch nicht Andeutungen eines zweiten Ringes haben sich je gezeigt.

Alle diese Tatsachen erscheinen beweiskräftig genug dafür, daß die Vossiussche Ringtrübung eine traumatische Veränderung ist, wie dies bis auf Hesse alle Autoren aus ihren Befunden geschlossen haben, und daß sie im Momente des Traumas zustande kommt. Von einer nachträglichen Ablagerung aus dem Kammerwasser kann aus den aufgezählten Gründen keine Rede sein.

Daran ändert auch der wiederholte Versuch Hesses nichts, das typische klinische Bild der Ringtrübung umzugestalten und den Ring durch eine Scheibe zu ersetzen. Eine Umgestaltung, die zwar im Sinne seiner Hypothese liegen würde, die aber ebenfalls den Tatsachen zuwider läuft. Ein wirklicher Ring ist da und es haben ihn alle bisherigen Autoren gesehen. Seine Breite und sein Lumen sind an der Spaltlampe genau meßbar und er setzt sich, im Unterschied zu seinem Lumen, aus Pünktchen zusammen. Die Untersucher, denen das Spaltlampenmikroskop zur Verfügung stand, haben das bestätigt. Die bekannte, nicht immer gleich deutlich nachweisbare graue Scheibe, die das $\mathrm{Pu}$ pillargebiet innerhalb des Ringes erfüllt und die Hesse ihrer Zusammensetzung nach mit dem Ring identifiziert, besteht im Gegensatz zum Ringe nicht aus Pünktchen, sondern ist ungeformter Natur: Sie stellt wohl, wie wir das schon früher vermuteten (Z. f. A. 40, S. 217 ff. 1918) jenes Fibrin, oder ganz allgemein jenen Klebstoff dar, der zum Festkleben der Pünktchen im Bereiche des Pupillarrandes im Momente des Traumas Anlaß gibt, - setze sich nun der Ring, wie es Hesse annimmt, aus reinem Blut, oder wie wir es für wahrscheinlicher halten, zur Hauptsache aus Pigmentelementen zusammen. Nur ausnahmsweise sitzen Ringpünktchen vereinzelt oder in Gruppen auch außerhalb und innerhalb des Ringes.

In weleher Art und Gruppierung diese Pünktchen den Ring bilden, das habe ich nach dem Bilde, welches das Spaltlampenmikroskop liefert, in Abb. 201 meines Atlas d. Splm. wiedergegeben. Es ist gerade dieser Fall wiederholt sehr sorgfältig, auch von zweiter und dritter Seite, untersucht und abgebildet worden und es kann über die Details der Ringgestalt, seiner Breite, seiner Irregularitäten, die sehr oft kontrolliert wurden, kein $Z$ weifel bestehen. Man wird doch in diesem wie in den anderen am Spaltlampenmikroskop untersuchten Fällen 
zugeben müssen, daß ein wirklicher Ring vorhanden war, der keinen Anlaß zur Verwechselung mit einer Scheibe geben kann.

Tch verfüge noch über einen zweiten genauer untersuchten Fall von Vossiusscher Ringauflagerung, den ich vor drei Jahren beobachtete und dessen Ring ich hier als Bestätigung des eben. Gesagten wiedergebe. Man beachte auch hier wieder: Ein wirklicher Ring liegt vor, er setzt sich auch hier wieder aus den punktförmigen, bräunlich glitzernden Elementen zusammen, die eben einzig dem Ring angehören. Dieser Ring wurde einen Tag post trauma beobachtet, zu einer Zeit, da die Pupille weiter war wie der Ring und ein noch 2 mm hohes Hyphaema bestand! Das Blut hat in diesem Falle ebensowenig wie in allen anderen Fällen, zu weiteren Ringbildungen Anlaß gegeben!

Abb. $3 b$ gibt ein nasal unteres Ringstïck $R$ wieder, wie es bei 25 facher Linearvergrößerung aussah. Abb. 3a zeigt den Ring bei Durchleuchtung. (Dem 8jährigen. Knaben war eine Kastanie gegen das linke

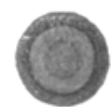

Abb. $3 \mathrm{a}$.

R

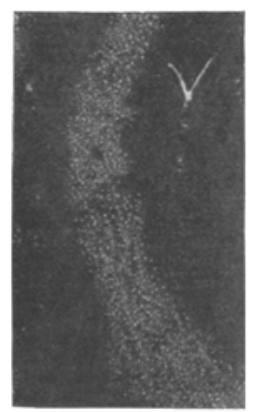

Abis. $3 \mathrm{~b}$. Auge geworfen worden. Starke Forderkammerblutung, nach Rückgang der Blutung am folgenden Tage Vossizussche Auflagerung.)

Das klinische Bild der Vossiusschen Ringauflagerung lehrt also ganz allgemein, daß der Ring eine Kontusionsfolge darstellt. Auch in den allerfrühest beobachteten Fällen war die Ringbildung bereits definitiv entwickelt und niemals warde eine nachträgliche Zunahme der Auflagerung durch Apposition beobachtet, insbesondere auch damn nicht, wenn die vordere Kammer reichlich Blut enthielt. Das sind Momente, welche die Entstehung der Auflagerung im Augenblicke des Traumas höchst wahrscheinlich machen, und die Bedeutung des Traumas als conditio sine qua non dartun.

Das Lumen des Ringes entspricht stets ungefähr der mittleren Pupillenweite und es ist dadurch die bisherige Annahme gestützt, daß der Ring eine Art Abklatsch des Pupillensaumes darstellt. Ich zitiere nochmals den Casparschen Fall (Verdeckung eines Teils des Rings durch ein Koagulum, die betreffende Ringstrecke kommt nach Resorption des Koagulums zum Vorschein!), welcher mit der Exaktheit eines Experimentes lehrt, daß der Ring nicht aus der Vorderkammer nachträglich (post trauma) abgelagertes Blut sein kann, sondern da $B$ er eine durch das Trauma bedingte, vor der Koagulumablagerung entstandene Ausscheidung auf die Vorderkapsel darstellt. Ich habe ${ }^{1}$ ) (was Hesse entgangen zu sein scheint), die Frage offen gelassen, ob die genannte,

1) Z. f. A., 40. 220. 1908 . 
traumatisch bedingte Ausscheidung (der Pupillenabklatsch) durch eine mechanische Anpressung des Pupillenrandes an die Linsenkapsel, oder aber durch eine momentane Auspressung von Gewebsflüssigkeit (Lymphflüssigkeit?) und corpusculären Elementen (elementare Pigmentkörnchen, vielleicht auch Blutkörperchen) aus der (ris zustande kommt. Die Gelegenheit zum Festkleben dieser Elemente auf der Kapsel wird dort die günstigste sein, wo die Iris der Kapsel direkt aufliegt.

Der Ring ist bei letzterer Annahme genetisch den Pigmentringen auf der Vorderkapsel, wie sie die Iridocyclitis liefert, in gewissem Grade vergleichbar. Finden wir ja auch dort die Ringbildung - die corpusculären Elemente - dem Pupillarsaum konform geordnet, das (amorphe) Exsudat dagegen - i. e. den Klebstoff - als Scheibe über das ganze Pupillargebiet (und nur über dieses!) ausgebreitet!

\section{Nachträgliche Linsenveränderungen nach Vossinsscher Ringtrübung.} (Abb. 3c).

Der oben erwähnte Knabe H. Sch. wurde von mir im Jan. 1922, zweieinviertel Jahre post trauma, kontrolliert. Es besteht dauernde leichte Mydriasis. Die vordere Rinde des verletzten Auges weist heute im Abspaltungsstreifen die feinen Punkttrübungen der Abb. $3 \mathrm{c}$ auf, von denen zur Zeit der Verletzung und einige Wochen nacher niehts zu sehen war, und die am anderen Auge völlig fehlen. Sie sind also offenbar eine Spätfolge der Koniusion, so daß künftig auf solche zu fahnden sein wird. Die übrigen Trübungen, insbesondere die V-förmige Auflagerung Abb. $3 \mathrm{~b}$ sind heute verschwunden.

Bei dem anderen, oben zitierten Fall H. ergab die Nachkon-

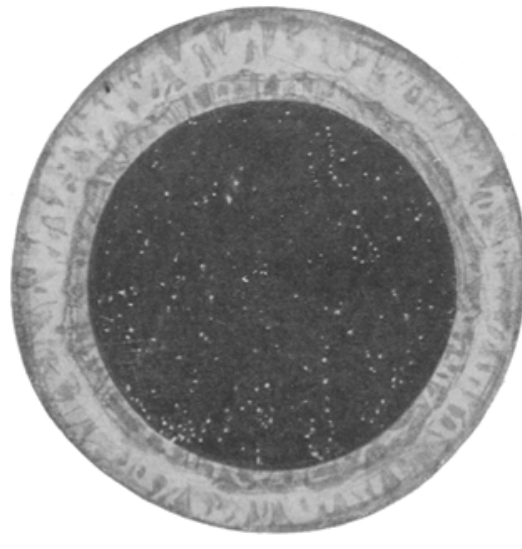

Abb. 30. trolle drei Jahre post trauma das Fortbestehen und die leichte Vergrößerung der in der ersten Mitteilung beschriebenen kleinen subkapsulären Trübung. An die Trübung hat sich eine Vakuole angeschlossen. Im übrigen ist die Linse dieses Patienten intakt.

Es scheint also, daß bei Vossiusscher Trübung nachträglich noch Linsenveränderungen geringfügiger Natur auftreten können. 
Faltenartige Bildungen des (yordern) Chagrinsubstrates ( $A b b .4)$.

Dieser Fall stellt wohl eine große Seltenheit dar. Etwas ähnliches haben wir bisher nie beobachtet.

Der 31 jährige Militärpatient E. B. hat rechts Überreste einer angeblich vor 3 Jahren überstandenen Iridocyclitis mit tiefer parenchymatöser Keratitis. Linkes Auge frei. Reste von Lungentuberkulose. Die Folgen der Iritis bestehen in vereinzelten unregelmäBigen Prominenzen des Pupillarpigmentsaumes (siehe Abb. 4), einer von der Linse losgelösten, sehnenartig am oberen imneren Pupillarsaum sich ausspannenden weißen, stellenweise pigmentbedeckten Membran $\mathrm{E}$ (s. Abb. 4 rechts oben) und zwei amorphen Pigmentklumpen auf der Vorderkapsel im temporalen Pupillargebiet, sowie aus einigen feinen Exsudatfleckchen, die bei Einstellung der vorderen Chagrinierung besonders dentlich sind (vgl. Abb. 186 v. 187 d. Atl. d. Splm.). Stellt man die Vorderkapsel ohne Chagrin ein, beobachtet man also im diffusen Licht, nicht im Spiegelbezirk, so erscheint die

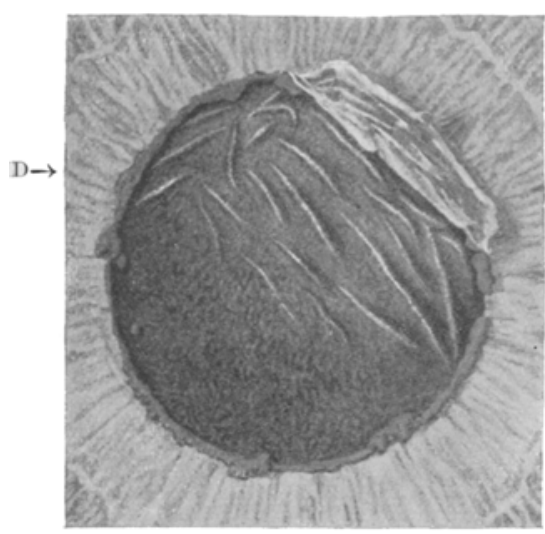

Abb, 4 . Linsenvorderfläche vollkommen glatt. Im. Chagrin dagegen werden die merkwïrdigen, plastischen Falten der Abb. 4 sichtbar. Es sind ca. $0,05 \mathrm{~mm}$ breite, bis zu $1 \mathrm{~mm}$ lange Wülste vom Typus der Falten eines dünnen Häntchens (doch fehlen Faltenreflexlinien, außer an einer $\langle-\mathrm{E}$ Stelle bei D). Die Oberfläche der Falten zeigt Farbenschillern. Die Firsten besitzen jedoch jene feine Epithelfelderung nicht, welche ihrer Umgebung zukommt und jeden normalen Chagrin auszeichnet. Sie erscheinen vielmehr glatt. Ihre Lage, Richtung und Ausdehnung ändera die Fältehen nicht, ob wir die Pupille mit Pilocarpin verengen (entsprechend. Abb. 4), oder ob wir sie samt der Akkomodation mit Atropin lähmen. Höchstens hatte ich einige Male den Eindruck, daß die Faltchen bei Mydriasis vielleicht um ein weniges schmäler wurden. Am Mikrometer ließ sich jedoch eine Verschmälerung nicht nachweisen. Beobachtet man im diffusen licht (also ohne Chagrineinstellung), so sind im Faltenbereich feine streifig-wolkige Trübungen zu sehen, mit Sitz im Abspaltungsstreifen (Beobachtung im November 1921, 10 Monate nach Aufnahme von Abb. 4). Der Richtung nach entsprechen diese Streifen ungefähr den einzelnen Fältchen.

Nirgends ist die Iris an der Kapsel adhärent.

Die merkwürdige Veränderung ist von uns zunächst während 2 Wochen kontrolliert and bei enger und weiter Pupille durch Abbildungen festgehalten worden. Sie blieb während dieser Zeit vollkommen stationär. Tension $=n$, $R S=6 / 8, L S=6 / 5$. Akkommodationsbreite beiderseits $=8 \mathrm{D}$. Nach 10 Monaten war der Befund unverändert.

Da die Linsenoberfläche selber, wie das verschmälerte Büschel dartut, glatt und eben ist und da nicht die von uns geschilderten Kapselfalten vorliegen (Atl-d. Splm. Abb. 290, 391 ), wird wahrscheinlich, daß eine Veränderung nicht der Kapsel, sondern eines anderen Teiles des Chagrinsubstrates, vielleicht des Epithels, vorliegt. 
Im Gegensatz zu diesen „Chagrinfalten" sind Kapselfalten ohne Einstellung des Spiegelbezirkes sichtbar. Dabei ist in manchen Fällen von Kapselfaltung eine Chagrinzeichnung nicht mehr oder nur noch undeutlich zu. sehen. ${ }^{1}$ )

In Bezug auf die Genese liegt es nahe, eine Beziehung zu der Pupillarexsudatmembran anzunehmen. Offenbar stand letztere ursprünglich in solider Verbindung mit der Vorderkapsel, so daß an die Möglichkeit einer Einwirkung auf die Oberfläche

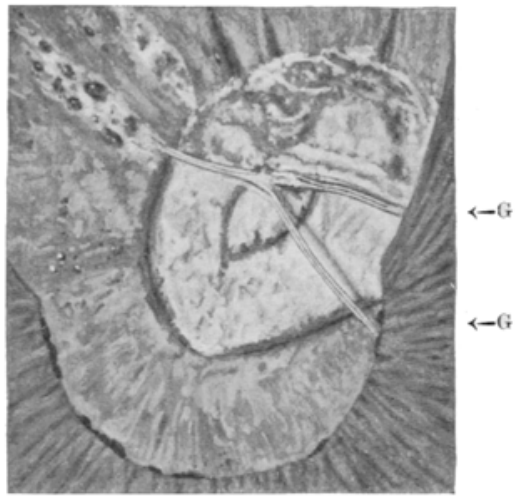

Abb. $4 \mathrm{a}$ der Linse zu denken ist. Eigentümlich ist, daß Atropin und Eserin die Konfiguration der Fältchen in keiner Weise zu verändern vermögen.

\section{Subkapsuläre Ansammlung Elschnigscher Kugeln nach Verletzung des Linsenäquators (Abb. 5 u. 6).}

Keulenförmige äquatoriale Flüssigkeitsschläuche (Abb. 7 u. 8).

In seiner Einführung in die Augenhelkunde (1901, S. 159) hat J. Hirschberg auf "Tropfen" aufmerksam gemacht, welche nach ihm nicht nur einen Bestandteil verschiedenster Stare bilden, sondern auch in der Nachstarhaut sitzen. Hirschberg identifiziert diese kugeligen Gebilde mit den besonders im Lupenspiegel deutlichen Nachstarvakuolen. Elschnig, (Kl. M.f. A. 1911, 49, 444) beschrieb, ohne Bezugnahme auf die Hirschbergschen Beobachtungen, anscheinend ähnliche Kugeln und untersuchte sie anatomisch. Er spricht sie als mit den sog. Bläschenzellen morphologisch übereinstimmende, durch Umwandlung von (gewucherten) Epithelien entstandene Gebilde an. Thr froschlaichähnliches Aussehen habe ich im Atl. d. Splm. in Abb. 288 wiedergegeben.

Während ich diese KugeIn in ihrer typischen Form und Ausdehnung bis jetzt nur bei Nachstar fand, sah ich sie kürzlich auch bei einer am

1) In einem Falle allerdings konnte ich sie sicher nachweisen. Bei dem 64 jährigen Herm M. D., mit beidseitiger Katarakt bei Myopie 9,0 D fand sich an der rechten, stärker getrübten Linse, Abb. 4a, im Pupillargebiet ein intensiv weißer Trübungsherd, der sich gegen die Umgebung durch eine riß. artige zirkuläre Furche (vgl. Text zu Abb. II und 12 des Abschnittes IV, dieses Arch. 108, 203) abgrenzte. Quer über diese Trübung zog eine gegabelte Kapselfalte in schräg horizontaler Richtung ( $\mathrm{Abb}$. $4 \mathrm{a}, \mathrm{gg}$ ). Die Falte zeigte bei passender Einstellung Chagringlanz. Unter den Falten und in deren Umgebung im durchfallenden Licht zahlreiche Vakuolen. 
unteren äußeren Äquator durch Perforatio bulbi beschädigten. im übrigen intakten Kinderlinse.

Die 7 jährige W. R. erlitt am 2. VII. 1920 eme Eisennagelperforation des rechten nasalen unteren Limbus sclerae.

3. VII. Uvea, besonders Iris, stark prolabiert, Iris temporal unten gerissen, nasal untere und hintere subpapsuläre Katarakt, letztere stärker axial, Blut in der Vorderkammer, Projektion gut. Irisabtragung, später Wiederholung der Abtragung. Bei Mydriasis Linsenrand A e, Abb. 5, anßer oben und temporal überall sichtbar, ebenso Zonula und (temporal unten) die Ciliarfortsätze (s. Abb. 5 bei o). Heilung mit ausgedehnter hinterer subkapsulärer Trubbung (21. X. 1922) und umschriebener, nasal unterer Trübung, nasal unterer Linsenrand eingekerbt.)

23. VIIT. R. S. $=6 / 36$.

$3^{1} / 2$ Monate nach der Verletzung (23. X.) sind am unteren äußeren Linsenäquator die subkapsulären Kugeln der Abb. 5 (25fache Linearvergrößerung,

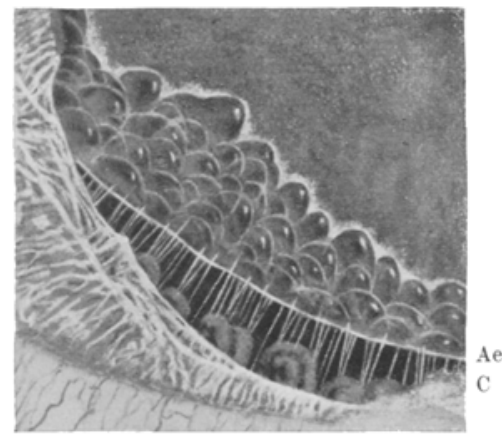

Abb. כ.

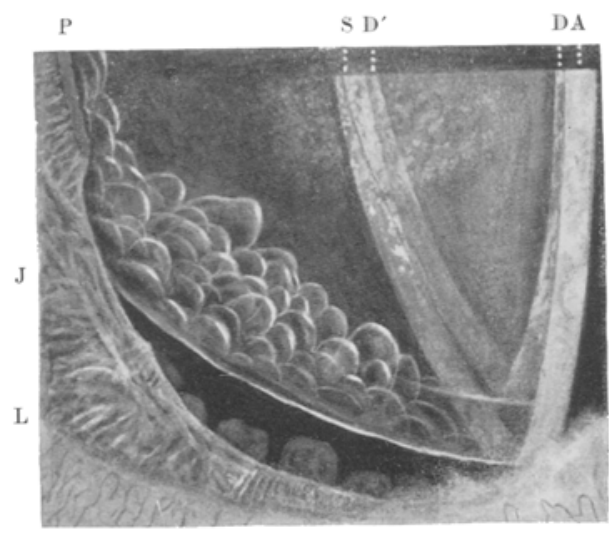

Abb. 6.

Beobachtung im direkten licht) zu sehen. Sie liegen froschlaichähnlich nebeneinander. Noch lebhafter, als bei direkter Beleuchtung, treten die Kugeln in Frscheinung, wenn (wie das Abb. 6 zeigt), das Licht auf die hintere Subkapsularkatarakt $=\mathrm{S}$ geworfen wird. Die jetzt im Dunkeln liegenden Kugeln erhalten vom Büschel =AS her Seitenlicht, wodurch sie besonders plastisch hervortreten. $\quad(A=$ Linsenvorderfläche, $S=$ Linsenhinterfläche mit subcapsulärer Katarakt, $\mathrm{D}, \mathrm{D}^{\prime}=$ zweite Diskontinuitätszonen, $\mathrm{P}=$ Pupillarsaum, $\mathrm{I}=\mathrm{Iris}$ mit ausgedehntem Sphincter- und Stromailß, $L=$ Limbus.)

Die ausgedehnte hintere Subkapsulärkatarakt setzt sich mittelst Ausläufer. zu der nasal unteren Trübung (Verletzungsstelle) fort. Die hintersten Kugeln erscheinen bei direkter Belichtung von einer feinen grauen Trübung glorienartig begrenzt. Braune rundliche Ciliarfortsätze überragen den Irisrand. Bündelweise gruppierte Zonulafasem durchspannen den circumlentalen Raum, wobei je ein einzelnes Bündel einem Ciliarfortsatz entspricht (doch steigen auch aus den Tälern Fasern auf).

Verfolgen wir den Linsenäquator temporalwärts nach oben hin, so verschwindet er hinter der hier intakten Iris, und es treten unter dem Pupillenrand an Stelle der Kugeln flach abgeplattete subkapsuläre, radiär gerichtete Schlänche von Keulenform zutage an die sich axialwärts vereinzelte rundliche oder ovale eben- 
falls abgeplattete Vakuolen anschließen. Diese sind in Abb. 7 im durchfallenden Lichte (Linsenlicht), in Abb. $8 \mathrm{im}$ auffallenden Lichte dargestellt. Bei letzterer Beobachtungsweise ist in der Umgebung der (ähnlich den Kugeln glasig glänzen-

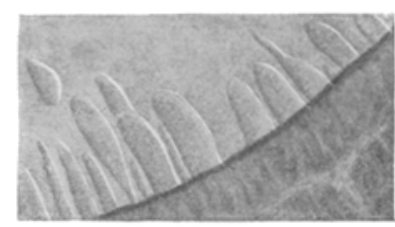

Abb. 7.

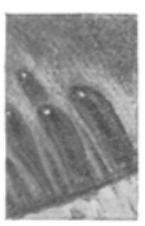

Abb. 8.

den) Keulen die Linsensubstanz leicht streifig getrübt etwa wie die Linsensubstanz in der Umgebung von Wasserspalten leichte diffuse bis streifige Trübung aufweist. Weiterer Verlauf wegen Abreise des Kindes nicht beobachtet.

Es hat somit im vorliegenden Falle eine Perforatio bulbi, welche den nasal-unteren Linsenrand beschädigte, zu einer vorderen und hinteren Subkapsulärkatarakt, besonders der axialen Linsenpartien geführt und es traten einige Monate später unter der temporal-unteren, sicher nicht lädierten Linsenkapsel typische, froschlaichähnliche Kugeln auf, welche nach Größe, Form und Gruppierung durchaus den von Hirschberg, Elschnig und uns beschriebenen Kugeln entsprechen. An ihrer Stelle finden sich im oberen Linsenbezirk langgestreckte, subcapsuläre radiäre Flüssigkeitsschlöuche von Keulenform. Ob diese letzteren genetisch mit den Kugeln identisch sind, läßt sich nicht ent. scheiden.

Die Form dieser Schlauche bietet insofern Interesse, als sie lebhaft an die in ihrer Entstehungsweise noch so rätselhaften keulenförmigen (peripheren) Coronartrübungen erinnert (vgl. Abb. 213 des Atl. d. Splm.). Es erscheint bemerkenswert, daß bei Coronakatarakt ausnahmslos gerade nur die äquatorialen Rindenpartien diese morpholo. gisch schwer verständlichen Coronarkeulen aufweisen. Und auch im vorliegenden Falle von traumatischer Schädigung liegen die Keulen ausschlieBlich äquatorial. Vielleicht steht dieses Verhalten mit der Linsenstruktur insofern im Zusammenhang, als diese äquatorialen Partien nahtrei sind, so daß also in diesem Abschnitte der Faserung, im Gegensatz zu anderen Linsenpartien, ein ausschließlich radiärer Verlauf zukommt. (Ủber die Abhängigkeit von Vakuolenform und -anordnung von der Faserrichtung vgl. Abb. 198 und 199a des Atl. d. Splm.)

Es führen vielleicht derartige Beobachtungen äquatorialer keulenförmiger Flüssigkeitsansammlungen zum Verständnis der keulenförmigen Trübungen bei Coronarkatarakt: Man könnte sich die letztere als aus derartigen Flüssigkeitsansammlungen hervorgegangen denken. 
Schleuderung von Linsenmassen in den Glaskörker (Abb. 9 u. 10).

Bei Perforatio lentis sah ich am Spaltlampenmikroskop in den Glaskörper geschleuderte und dort mit dem Gerüst sich bewegende Linsenmassen, so im Falle Abb. 9.

Der 17 jährige E. H. erlitt am 20. IX. 1920 eine Perforatio bulbi sinistri durch einen $00036 \mathrm{~g}$ schweren scharfkantigen Stahlsplitter. Temporale Hornhaut-, Iris- und Linsenwunde; der schüppchenförmige Splitter steckt in der temporalen hinteren Netzhaut. Am folgenden Tage zeigte das Spaltlampenmikroskop auf der temporalen Linsenhinterfläche die lanzettliche hintere Perforationswunde der Abb. 9, W (24fache Linearvergrößerung). Die Wunde läßt Aufblätterung der Linsensubstanz in konzentrische Lamellen erkennen. An die obere Wundspitze schließt sich eine erweiterte (an zwei Stellen dunkle) Naht N mit zugehöriger grobstreifiger Faserung an. Unten einige Vakuolen. Der Durchschlagskanal

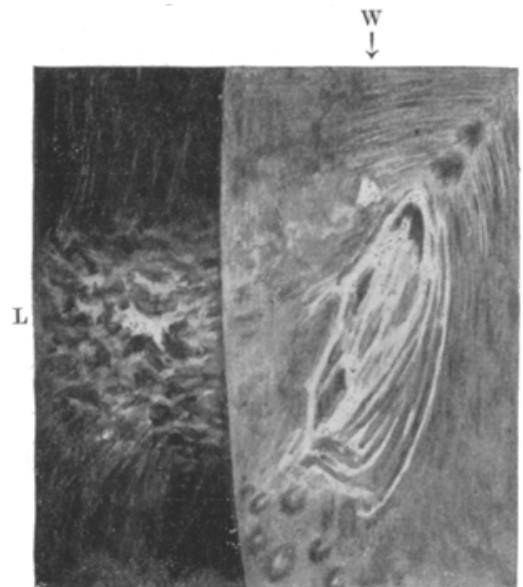

Ább. 9. geht weiter durch den Glaskörper (im Bilde links), wobei ihn dicht vor der Linsenwunde weg grauweiße wolkige Massen $L$ erfullen, die sich im vorderen Glaskörper nach rückwärts allmählich verlieren. Es handelt sich um mitgerissene Linsenflocken, welche in dem feinfädigen Glaskörpergerïst suspendiert sind und bei Bulbusbewegungen mit letzterem hin und her schwanken, um schließlich wieder an die ursprüngliche Stelle zuruickzukehren.

Der Splitter wird mittels Innenpolmagnet in die Vorderkammer gebracht und durch die Perforationswunde extrahiert. Die Katarakt mußte später disdiscidiert werden.

Mit dem Spaltlampenmikroskop gelang somit im vorliegenden Fall der Nachweis, daß ein perforierender Splitter trotz kleiner hinterer Perforationswunde Linsensubstanz in Form von kleinen. Fetzen in den Glaskörper riß.

Sandte man im vorliegenden Falle das Lichtbüschel an der hinteren Linsenwunde vorbej, so leuchteten deren Ränder lebhaft rot auf. Es handelt sich um jenes, im Text zu Kataraktfig. 42 des III. Abschnittes (dieses Arch. 108, 190) kurz erwähnte Phänomen des roten Aufleuchtens von Medientrübungen bei Beleuchtung des Fundus mit dem Büschel der Spaltlampe. Dieses Aufleuchten besteht nach unseren Untersuchungen aus dem Sichtbarwerden des roten Funduslichtes zufolge diffuser Zerstreuung desselben durch ein trübes Medium oder durch eine unregelmäBig brechende Fläche. Es soll in einem späteren Kapitel auf dieses Phänomen an Hand von Beispielen näher eingetreten werden.

Gelegentlich kann die hintere Perforationsöffnung der Linse Bilder 
bieten, welche an die Austrittsöffnung von Projektilen aus Körpergeweben, besonders aus geschlossenen Höhlen, erinnern: Die Ausschußöffnung ist wesentlich größer als die Einschußöffnung, weil der Fremdkörper Gewebsteile gewaltsam mit sich fortreißt, deren Austritt die Wunde vergrößert.

In Abb. 10 (ca. 12 fache VergröBerung) handelte es sich um ein derartiges Perforationsbild bei dem 18 jährigen Pl, E.

Am 6. XI. 1920 beim Hämmern auf Eisen Perforatio bulbi dextri. 11/2-2 mm lange vertikale Linearwunde temporal- unten von der Corneamitte, ihr gegenüber eine Perforationswunde der Linse mit adhärentem Pupillenrand, starke vordere Rosettenkatarakt und beginnende Trübung der ganzen Linse, kein rotes Licht aus dem Fundus. (Splitter nicht entfernbar, steckt in der Sclera, dicht temporal Papille.) Visus $=$ Handbewegungen. Nach teilweiser Aufhellung der Katarakt (17. bis 27 . XI.) wird die mächtige dunkle dreikantige Höhle der Abb. 10 sichtbar, welche eine optisch leere Liücke in der Linsensubstanz darstellt. In normalen Büschel sind vorderer Kapsel-, $\mathrm{Ab}$ spaltungs- und Alterskernstreifen (Abb. $10 \mathrm{C}, \mathrm{A}$, N) noch unterscheidbar. Ein Tejl der Höhle wird durch einen dicken, unregelmäßig geschichteten vakuolenhaltigen Pfropf $P$ eingenommen ( $A$ bb. 10), der hinten in den Glaskörper hernienartig vor-

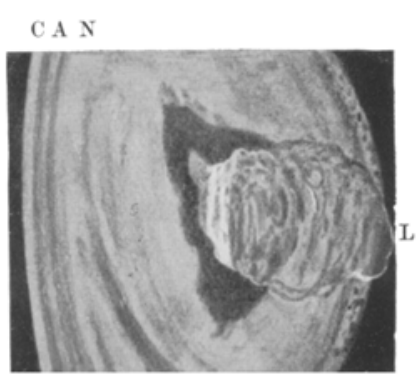

Abb. 10 . ragt. - Weiterer Verlauf: Discission am 27. XI. 1920. Es resultiert Aphakie. Dichtes Narbengewebe neben Papille. Röntgenbild positiv. Sideroskop (Hertel) leichter Ausschlag.

In diesem Falle besitzt der Perforationskanal eine wesentlich größere Austritts- als Eintrittsöffnung. Der Fremdkörper riß beträchtliche Partien, hauptsächlich des Kerngebietes, mit, an ihrer Stelle eine mit Flüssigkeit gefüllte Lücke lassend. Die mitgerissenen Massen stecken in der hinteren Perforationsöffnung und ragen in den Glaskörper. Wir haben eine Wirkung vor uns, welche derjenigen perforierender Geschosse vergleichbar ist.

Pupillare Exsudatvaseularisation (Abb. 11, 12).

Bei Spaltlampenbeleuchtung findet man die Pupillarexsudate nicht selten vacularisiert. Im durchfallenden Licht (Linsenlicht) treten gröbere Stämmchen und Capillaren als scharfe Linien hervor (Abb. 11). Im auffallenden Licht dagegen (Abb. 12) ergeben sich durch die Prominenzen, welche die Capillaren hervorrufen, Flächenreflexe, die etwa denen der Limitans interna retinae jugendlicher Individuen vergleichbar sind. Sie erteilen dem Exsudat ein charakteristisches Oberflächenrelief, das allerdings nur bei Einstellen des Spiegelbezirkes sichtbar wird. Abb. 11 (durchfallendes) und Abb. 12 (auffallendes Licht) geben Jie nasale Partie der linken Linsenvorderfläche der 36 jährigen Frau B. wieder, welche seit sechs Jahren an schleichender Iridocyclitis unbe- 
kannter (tuberkulöser?) Atiologie leidet. L $S=\sec w a c h 1 / 10$, beginnende Cataracta complicata.

In bezug auf den Typus dieser Gefäßnetze ist noch folgendes zu erwähnen: Vasa afferentia und eferentia verhalten sich hier anders, als z. B. bei Gefäßneubildung der Hornhaut, insofern, als sie bei letzterer gewöhnlich dicht neben einander und parallel, im Pupillarexsudat dagegen in größerer Distanz und in unregelmäßig wechselnder Richtung verlaufen. Die Ursache dieses verschiedenen Verhaltens liegt wohl

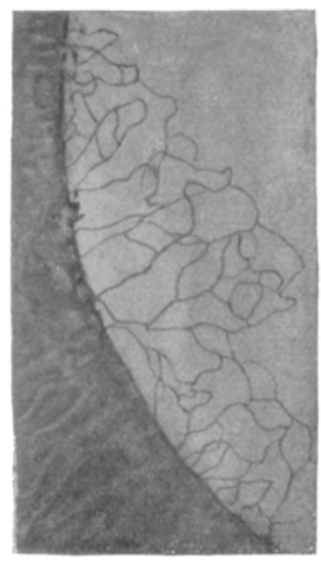

Abo. 11 .

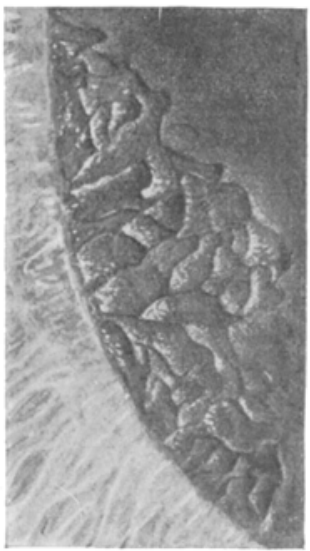

Abb. 12

darin, daß die Verlaufsrichtung im Exsudat nicht, wie in der Cornea, durch eine besondere Gewebsstruktur beeinflußt wird. Viel Ähnlichkeit in bezug auf Endarkaden und Anastomosen zeigt dagegen das Gefäßnetz des Pupillenexsudates mit dem normalen Randschlingennetz des Limbus (vgl. Abb. 9a des Atl. d. Splm.).

\section{Gleichmäßige Punktauflagerung des Pupillargebiets bei Perfortio bulbi}

(Abb. 13).

Bei dem 2ljährigen E. Sch. fand am 11. Dezember eine Perf. bulbi sinistri durch einen Eisensplitter statt. Die Perforation wurde von dem behandelnden Augenarzt nicht diagnostiziert (Perforationsstelle im Bereiche der nasalen Pinguecula, Iris und Linse nicht verletzt) und Pat. trat, nachdem er Umschläge gemacht, 8 Tage später in klinische Behandlung. Es fand sich ophthalmoskopisch ein Eisensplitter der Netzhaut, ca. 4 P D unterhalb Papille. Extraktion mitiels Imnenpolmagnet am 9. XII., Gewicht des Splitters $0,0089 \mathrm{~g}$.

Heilungsverlauf durch mehrere Wochen anhaltende Bulbusreizung verzögert. Pupille erweitert sich ungenügend auf Atropin, keine hinteren Synechien. Glaskörper diffus trüb, mit Spaltlampe dichte weiße Punkteinlagerungen (Glaskörperinfelktion?). Tachdem der Visus einige Wochen lang $=1 / 4^{-1 / 3}$ (H 3,0 ) gewesen war. trat Abnahme desselben ein. 
Anfang Februar 1922 wird eine lochähnliche Bildung der Macula beobachtet (scheinbares Loch von 1/2 PD, mit weißem Rand, erste Beobachtung durch Dr. Lüssi). Cystoide Entartung der Umgebung. $S=$ Finger in $1 \mathrm{~m}$. Ständige leichte Ciliarinjektion.

Bei der ersten Untersuchung (also vor der Extraktion) bestand das Pupillenbild der Abb. 13. Der mittleren Pupillenweite entsprechend überdecken die Vorderkopsel weiße, gleichmäßig verstreute Punkte, von der Größenordnung 10-20 Mikra und weniger. Bei weiter Pupille (Abb. 13) hebt sich die Punktzone gegen die völlig punktfreie Umgebung scharf als kreisrunde Scheibe ab. Diese Scheibe blieb im vorliegenden Falle mehrere Wochen lang auch noch nach der Extraktion in unveränderter Ausdehnung bestehen. 21/2 Wochen nach der Extraktion waren

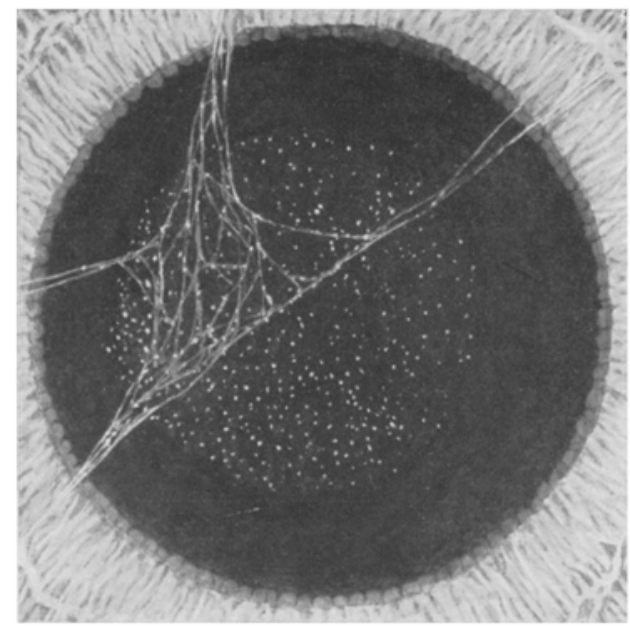

Abb. 13.

die Punkte spärlicher und hatten zum. Teil die braune Farbe von Pigment angenommen.

Den mittleren und oberen Abschnitt des Pupillargebietes nahm schon bei der ersten Untersuchung ein zierliches Fadennetz ein, das durch mehrere Zipfel schürzenartig mit der Krause in Verbindung stand (Abb. 13).

Nicht immer ist es leicht - besonders nicht bei heller Iris und sehr zarten Fäden -, die Krausenverbindung solcher Fadennetze zu erkennen und die Feststellung geschieht oft erst unter Zuhilfenahme der Mikrobogenspaltlampe. Leichter dagegen läßt sich immex nachweisen, daß die Fäden entsprechend der Lage der Krause wesentlich vor dem Pupillarsaum sich ausbreiten. Wer nicht auf die Verbindung mit der Krause achtet, kann eventuell, besonders bei Perforationsverletzungen, solche Fadennetze als Fibrinngerinsel ansprechen und auf Entzündung beziehen. - Das zweite Auge zeigt allerdings in den meisten Fällen übereinstimmende Fadengebilde. Auch der weitere Verlauf kann die Natur der Fadennetze aufklären. 
Die Punktauflagerungen sind im vorliegenden Falle offenbar der Ausdruck einer Exsudation, welche ja, wie bei jeder Iritis, ausschließlich oder fast ausschlieBlich in das Pupillargebiet stattfindet, während die hinter der Iris gelegenen Partien freibleiben. Bezeichnend ist der auffallend stationäre Charakter dieser Punkte. Trotzdem die Pupille fortan wesentlich weiter war als der Scheibe entsprach (Atropinwirkung), und trotzdem bei der Extraktion des Splitters eine kräftige Vorderkammerblutung auftrat (der Splitter wurde nach dem Vorgange Haabs um die Linse herum in die Vorderkammer befödert und aus dieser mittels Lanzenschnitt entfernt), änderte sich die Scheibengröße nicht. Man darf also daran denken, daß der ganze weiße Punktbelag vielleicht im Momente der Perforation oder bald nachher zustande kam, wahrscheinlich wenigstens mit der Anwesenheit des Splitters im Auge in irgend einer Beziehung stand.

Mit der Vossiusschen Ringauflagerung kann unser Punktbeschlag schon deshalb nicht verwechselt werden, weil die Punkte weiB, relativ grob und gleichmäBig über das ganze Pupillargebiet verteilt sind. Beachtenswert ist in diesem Falle schlieBlich doch die cystoide Maculadegeneration (Pseudolochbildung, über diese vgl. Verf. Klin. M. f. A. 66, 343, 1921), die schließlich unter Visusbesserung (nach 1/2 Jahr Visus $=6 / 8$ ) wieder völlig verschwand.

Die Abdrängung trüber Linsenpartien nach der Tiefe und die daraus sich ergebenden Folgerungen für Linsenwachstum und Kernbildung (Abb. 14-25).

Im AtI. d.Splm. habe ich über einen Fall von Kataraktabdrängung berichtet, welche bei einem Manne des fünften Jahrzehnts nach Con-

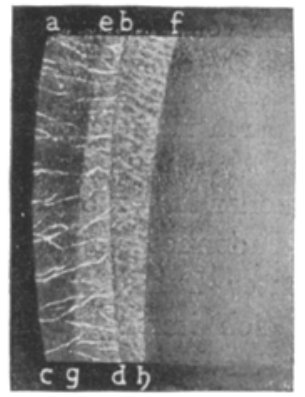

Abb. 14 tusio bulbi nachweisbar war (vgl, die dortige Abb. 277a und b). Seither habe ich weitere derartige Beobachtungen gesammelt, welche ich ihrer theoretischen und praktischen Bedeutung wegen im Nachstehenden mitteile.

Der zweite Fall ist dem in Abb. 277 abgebildeten ähnlich.

2. Beobachtung (Abb. 14, vgl. auch Abb. 27 u. 28). Der 1880 geborene Pf. aus D. erlitt vor 15 Jahren eine Kontusion des rechten Auges durch Anfliegen einer Holzkugel beim sog. Hornussen. Er wird von uns seit $2 \frac{1}{2}$ Jahren an der Spaltlampe kontrolliert. Heute, also 15 Jahre post trauma, $\mathrm{R} S=$ Finger in $1 \mathrm{~m} ; \mathrm{L} S=6 / 5$ Glbn.

Das rechte (verletzte) Auge zeigt folgenden Befund: $T=n$. Vorderkammer axial leicht vertieft, Iris hochgradig atrophisch, stellenweise durchscheinend, Iridodialyse von $3,5 \mathrm{~mm}$. Nach unten retinales Blatt flächenhaft vom Stroma losgelöst, in weiter Ausdehnung $2 \mathrm{~mm}$ unterhalb Pupillenmitte auf einem Kapselstar adhärent. Die durchscheinend fleckig getrubte linse ist in sagittaler Richtung 
verdünnt. Der sagittale Durchmesser beträgt nicht ganz $2 / 3$ desjenigen der gesunden Linse. Die vordere Rinde ist größtenteils klar, die hintere ist nicht deutlich übersehbar. In der subcapsulären Zone (Abb. 14, Zone a, b, c, d) liegen feine Trübungsstreifen und Flecken, welche zum Teil Faserrichtung einnehmen. Über diesen Streifentrübungen fehlt vielfach der Chagrin, so daß sie dunkle Unterbrechungen des letzteren darstellen. Sie verhalten sich also wie Kapselstare. Die darunter liegende klare Rinde ist axial am dicksten, peripher verjüngt sie sich auf etwa die Hälfte. Ihre Diskontinuitätsstreifen konvergieren peripher $(\mathrm{Abb}, 27,28)$, ein abnormes Verhalten, auf das wir weiter unten zurücklommen. Auf diese klare Rinde folgt die dichte gleichmäßige Trübungsschicht $e, f, g, h$ (Abb. 14). Diese Schalentrübung umschlieBt den leicht diffus getrübten Kern. Soweit durch die Trübungen hindurch erkennbar, bestehen im hinteren Linsenabschnitt ähnliche Verhältnisse. Eine lucide Schicht scheint auch in der hinteren Rinde vorhanden zu sein. Doch ist diese Beobachtung unsicher.

Die Dicke der vorderen luciden Rinde beträgt heute axial $1 / 4$ der gesamten Linsendicke (schmales Büschel und Okularmikrometex). Axial ist sie sehätzungsweise $1 \frac{1}{2}$ mal so dick wie die Hornhaut.

Es hat also im vorliegenden Falle das sehr schwere Trauma eine Atrophie der Iris, eine Reduktion der Linsendicke auf weniger als zwei Drittel der normalen und eine ausgedehnte Trübung der Linse zur Folge gehabt. Feine, noch vorhandene Subcapsulärtrübungen machen wahrscheinlich, daß die Cataracta traumatica ursprünglich subcapsulär lag. Sie wurde dann durch neugebildete lucide Substanz in die Tiefe abgedrängt, wo sie heute die gleichmäßige Trübungsschale e f $\mathrm{g} h$ darstellt. Die Dicke der neugebildeten Schicht beträgt heute, 15 Jahre nach dem Trauma, scheinbar etwa das anderthalbfache der Horn. hautdicke.

3. Beobachtung (Abb. 15-17). Der jetzt 33jährige Augenarzt Dr. M. erlitt in seinem 10. Jahre (1899) eine Kontusion des rechten Auges durch einen Pfeil, der das Oberlid des geschlossenen Auges traf. Der Visus war angeblich zufolge von Blutungen im Augeninnern längere Zeit aufgehoben. - Heute, nach 23 Jahren, $\mathrm{RS}=1 \mathrm{M} 1,0 ; \mathrm{L} \mathrm{S}=1 \mathrm{E}$. Linke Iris blaugrün, rechte bräunlichgrau ${ }^{1}$ ). Es ergibt sich bei Mydriasis folgendes Bild (Abb. 15): In der vorderen Linsenhälfte, dem vorderen Linsenpol ein weniges näher als dem Linsenzentrum (vgl, den Sagittalschnitt Abb. 17), somit in beträchtlicher Tieffe der Linse, breitet sich in konzentrischer Richtung (Abb. 17, K, schwache Vergrößerung) eine gleichmäßig dünne, intensiv weiße Trübungssohale aus (Abb. 15 von vorn betrachtet), welche in der Flächenansicht Rosettenform aufweist (vgl. die 7 strahlige Rosette in Abb. 15, 24fache Vergrößerung). Die Rosetteneinschnitte entsprechen je einer Naht, die Strahlen zwischen denselben der Faserpartie zwischen zwei Nähten. Die Nähte selber treten scharf als dunkle, nur wenig getrübte Linien hervor (Abb.15). Die Naht ist eine typische Vordernaht. Bezeichnend für letztere ist der kurze axiale Vertikalstreifen, der nach unseren Untersuchungen aus dem Vertikalast der vorderen Embryonalnaht hervorgeht. (Er mißt im vorliegenden Falle 0,5 mm.)

NasaI unten ist die Rosette insofern unregelmäßig, als hier zwei Zacken zu einem breiten, bis zum zugehörigen ${ }^{2}$ ) Äquator reichenden Streifen versehmolzen

1) S. Abschnitt Iris.

2) I. e. der betreffenden konzentrischen Zone zugehörigen. Jede konzentrische Zone, also auch jede Diskontinuitätszone hat naturgemäß ihren eigenen Äquator. 
sind. Das Verhalten am genannten Äquator ist bei etwas schwächerer Vergrößerung in Abb. 16 dargestellt. Es ist hier noch eine weitere, ein weniges oberfläch-

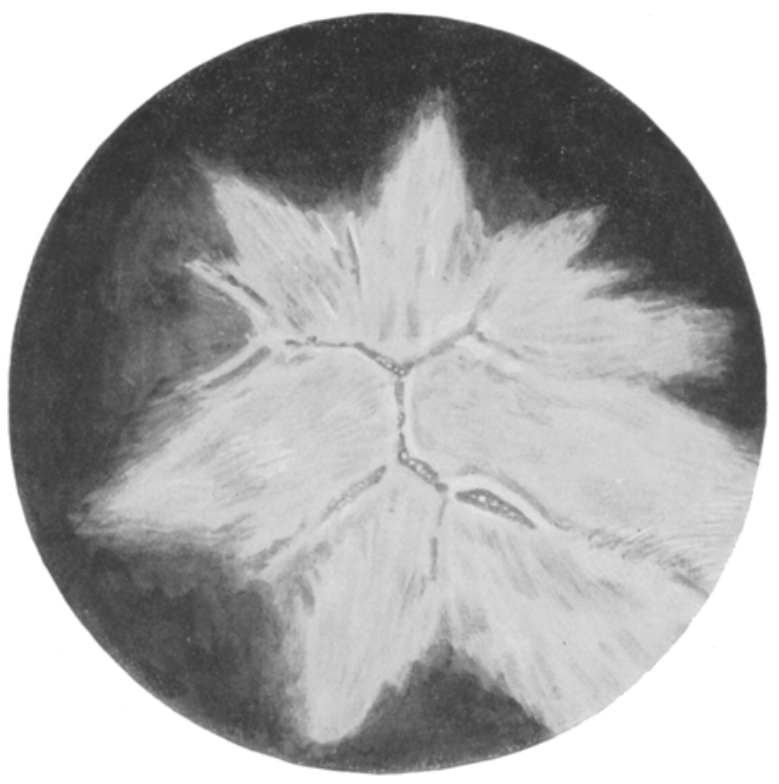

Abb. 15.

lichere Trübungszone $Z Z^{\prime}$ wiedergegeben $(L$ im Sagitalsehnitt $A b b .17)$, deren oberflächlichere Lage mit verschmälertem Büschel ohne weiteres zu erkennen ist. Diese setzt sich äquatorialwärts fort in die weiße äquatoriale Trübungslinie Z Z' (Abb. 16), welche die Umbiegungsstelle vorderer und hinterer F]ächentribungen repräsentiert.

Die Trübungslinie $Z Z^{\prime}$ (Abb. 16) zeigt, abgesehen von einigen feinen Biegungen, reine Kreisform, es schlagen sich hier vordere, mehr wolkige Flächen-

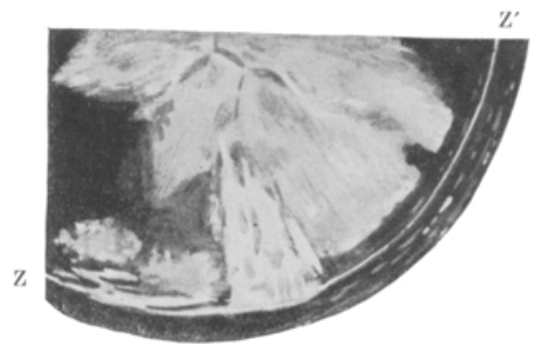

Abb. 16.

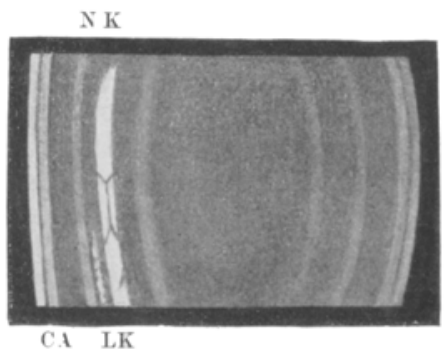

Abb. 17.

trübungen in hintere, in dex Abbildung nicht eingezeichnete, flächenhafte Keiltrübungen um. Wir haben also eine, durch die genannte Aquatoriallinie scharf begrenzte, plastisch erkennbare Kernpartie vor uns, deren Oberfläche sowoh! vorn wie hinten durch Flächentrübungen markiert ist. Diese äquatoriale Kern- 
begrenzung ist jedoch nur nasal, nasul unten und unten scharf nachweisbar. Der scheinbare äquatoriale Gesamtdurchmesser des (nirgends vollkommen luciden) Kerns beträgt $8 \mathrm{~mm}$. Nach oben von den genannten Flächentrübungen, setzt sich die Äquatoriallinie noch eine Strecke weit frei fort. Peripher von der linearen Zone $Z_{Z^{\prime}}$ sitzen einige kleine konzentrische Streifentrübungen (Abb. 16). Das Ganze ist von eimer dicken Schicht lucider Pinde umschlossen (vgl. Abb. 17, Sagittalschnitt). Der Alterskernstreifen (Abb. 17, $N$ ?) ist nicht sicher nachzuweisen, der Abspaltungsstreifen vorn und hinten deutlich ausgesprochen. Subcapsulär fehlt jede Trübung.

Kontusionskatarakte pflegen subcapsulär aufzutreten. Im vorliegenden Fall liegt die Katarakt in großer Tiefe, nämlich, wie der Sa gittalschnitt $\mathrm{Abb} .17$ lehrt, etwas vor der Grenze zwischen erstem. und zweitem Sechstel des sagittalen Linsendurchmessers. Berücksichtigen wir, daß 23 Jahre seit der Verletzung verflossen sind, daß ferner die verflossene Zeit zum großen Teile noch in die Entwickelungsjahre (10. bis 20. Jahr) fällt, so liegt es auch hier nahe, die tiefe Lage auf Abdrängung der Trübung durch Faserapposition zu beziehen. Die Verhältniswerte, die aus einer Reihe von Messungen mittels verschmälerten. Büschels hervorgehen, zeigen, daß sich die axiale Distanz zwischen Vorderkapsel und Rosette zu derjenigen zwischen Rosette und Hinterkapsel verhält wie 1 : 6 (genauer wie $6: 35$ ). Am gesunden, linken Auge dagegen verhält sich die Distanz zwischen Vorderkapsel und Alterskernstreifen zu der zwischen letzterem und Hinterkapsel wie $5: 35$. Es tiegt also die Katarakt des rechten Auges tiefer, als der linke Alterskernstreifen. Wir dürfen wohl aus diesem Verhalten den wichtigen Schluß ziehen, daß die Alterskernoberfläche des Iinken Auges die Oberfläche eines Entwickelungsstadiums der Linse repräsentiert, das in die Zeit nach dem Trauma des rechten Auges zu verlegen ist. Dabei ist vorausgesetzt, daß das Wachstum auf beiden Linsen ein ähnliches war, wie das übrigens aus der gleichen Dicke derselben mit Wahrscheinlichkeit hervorgeht.

Zu dem Schiusse, daß die Trübung tatsächlich in die Tiefe abge. drängt wurde, zwingen uns nicht nur die lange bekannten, von uns bestätigten, experimentellen Erfahrungen beim Tier und die übereinstimmenden Beobachtungen beim Menschen, sondern er wird auch dadurch sehr wahrscheinlich, daß die Trübung der Form nach mit einer Diskontinuitätszone übereinstimmt. Fine derartige Form muB die in die Tiefe gerückte Trübung bekommen, wenn sie ursprünglich subcapsulär lag. Auch die Fasern der Diskontinuitätszonen lagen ursprünglich subcapsulär und wurden dureh Apposition in die Tiefe gedrängt.

Die im vorliegenden Falle nachweisbare Trennung in zwei verschiedene, wenn auch sehr benachbarte Zonen, in die etwas tiefere Rosettenschicht und die ihr um ein weniges vorgelagerte zweite Zone 
( $\left.Z Z^{\prime}\right)$ scheint bei Kontusionskatarakt nicht so selten zu sein. Sie kann wohl nur durch systematisch fortgesetzte klinische und durch experimentelle Untersuchungen ihre Aufklärung finden. Denkbar wäre 1., daß die beiden Trübungen gleichzeitig getrennt entständen. Die

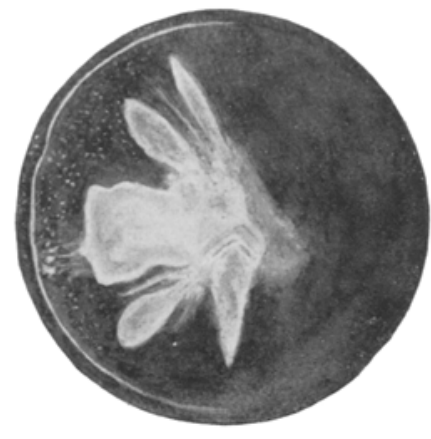

Abb. 18. eine würde subcapsulär, die andere etwa in der ersten Diskontinuitätszone liegen. 2. Die tiefere der beiden Zonen könnte zuerst entstehen und läge subcapsulär. Erst einige Zeit post trauma würde auch die zweite Zone auftreten, nachdem die erstere bereits in die Tiefe abgedrängt, wäre. 3. Die beiden Zonen wären ur* sprünglich einheitlich, sie würden aber durch neugebildete Substanz, die sich peripher einschiebt, getrennt. Ähnliche Möglichkeiten werden für die noch weiter peripher gelegenen kleinen konzentrischen Streifentrübungen zu gelten haben.

4. Beobuchtung (Abb. 18-20). Das rechte Auge des jetzt 52 jährigen Alfred Schl. wurde vor 35 Jahren von einem Geschobring bei einer Mörserexplosion getroffen. Der damals 17 jährige Patient flog durch die Gewalt der Verletzung $5 \mathrm{~m}$ weit zurück. Prof. Dufour soll neben Gesichtsverletzungen rechtsseitigen Hämophthalmus festgestellt haben.

Das Spaltbüschel zeigt das Bild einer partiellen Kata-

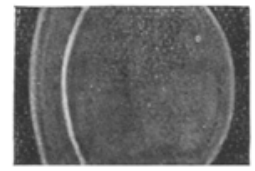
raltrosette (Abb. 18). Die Trübung breitet sich an der Grenze schätzungsweise zwischen erstem und zwyeitem Fünftel der Linsenachse aus (s. den Sagittalschnitt der Abb. 19. Die Messung mit dem Okularmikrometer ergibt axial als Verhältnis der Kataraktdistanz von der Vorderkapsel zur GeAbb. 19. samtdicke der Linse den Wert $8: 43$, also etwas weniger als $1: 5$. Etwas mehr nach der Peripherie hin erbält man schon Werte von $1: 4$ bis $1: 3$ ). Die zum Teil lanzettlichen Radien der Rosette haben verschiedene Breite und Form und sind ca. $2 \mathrm{~mm}$ lang. Am breitesten ist ein temporaler Flügel (Abb. 18). Bei erweiterter Pupille $(8 \mathrm{~mm})$ tritt temporal eine weiße, da und dort leicht gewellte Äquatoriallinie hervor, welche die Rosette umschlieBt, nicht aber den nasalen, rosettenfreien Teil der Linse (s. Abb. 18) Diese weiße Linie markiert den Äquator der Fläche, der die Rosette angehört. Letztere erreicht also diesen Aquator bei weitem nicht, was wohl damit zusammenhängt, daß die Rosette nicht oder nur wenig über die Nahtenden hinausreicht.

Die Fläche zwischen den Enden der Rosette und der trüben Aqquatoriallinie ist mit feinen Radiärflecken bedeckt (Abb. 18). Diese liegen eine Spur oberflächlicher als die Rosette. In der der Aquatoriallinie zugehörigen hinteren Fläche sieht man ganz spärliche Schlieren. Die Äquatoriallinie entspricht, wie mehrfache Messungen und der Vergleich mit der Pupillenweite ergeben, einem Kerndurchdurchmesser von ziemlich genau $8 \mathrm{~mm}$. (Die VergröBerung durch die Medien nicht berücksichtigt.) $\mathrm{R} \mathrm{S}=0,9 ; \mathrm{LS}=1$.

Der vorliegende Fall zejchnet sich dadurch aus, daB das Trauma 
vorwiegend nur die temporale Hälfte der Linse schädigte, nur dort zur Rosettenbildung, zu Staubtrübungen und zu einer trüben Äquatoriallinie führte. Letztere ist der in vorhergehender Beobachtung wiedergegebenen (Abb. 16), ebenfalls nur auf einen bestimmten Linsenabschnitt beschränkten äquatorialen Zone $\mathrm{Z} \mathrm{Z}^{\prime}$ an die Seite zu stellen. Wie dort, so tritt auch hier der relativ opake Kern plastisch aus der klaren Substanz hervor. Was die feinere Struktur der Rosette betrifft, so lehrt das sagittalle Büschel (Abb. 20, 25fache Vergrößerung D Kataraktschale), daB auch hier die Trübung aus einer gleichmäßigen, dichten weißen, scharf begrenzten Schale geringer Dicke besteht. Vorn ist der Schale stellenweise eine lichtschwache Netzzone aufgelagert, hinten eine feine Streifenzone (Abb. 20). Auch hier hat die Trübung jene Form, welche sie haben muß, wenn ihre Lage ursprünglich eine subcapsuläre war, mit anderen Worten, welche eine an ihrer Stelle befindliche Diskontinuitätszone haben würde. (Beobachtungsdauer ein Jahr.)

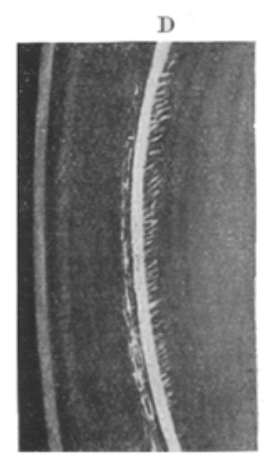

Abb. 20.

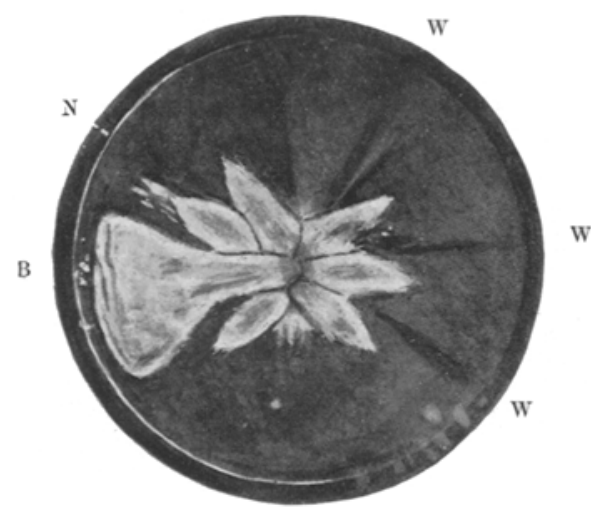

$\mathrm{Abb}, 2 \mathrm{~L}$.

5. Beobachtung (Abb. 2l). Vor vielen Jahren (angeblich ,einige Jahre vor dem Krieg"6, an die Zeit erinnert sich Patient nicht mehr) flog dem jetzt 45 jährigen An. Xaver bei der Schreinerarbeit ein größeres Hartholzstück mit Gewalt gegen das linke Auge. Seit dieser Verletzung schlechter Visus links. Heute R $\mathrm{S}=6 / 6$; $\mathrm{L} S \mathrm{~S}=$ Finger in $3 \mathrm{~m}$.

Bei seitlicher Beleuchtung zeigt das Pupillengebiet der Linse eine sternbis kometenförmige weiße Triibung (Abb. 21) von ganz ähnlicher Beschaffenheit wie im Falle Abb. 18. Schon makroskopisch erkennt man mit Hilfe der Parallaxe den Sitz der Trübung weit hinter dem Pupillarsaum. Benutzt man das verschmälerte fokussierte Spaltlampenbüschel zur Tiefenbestimmung (Abb. 21a, die dunklen Lücken $\mathrm{N}$ im Kataraktstreifen $\mathrm{K}$ sind die Nahtlinien, $\mathrm{C}$ Vorderkapsel, A Abspaltungsstreifen, D zweiter Diskontinuitätsstreifen, $\mathrm{K}$ Kataraktstreifen), so ergibt sich, dab die Trübung axial etwa an der Grenze zwischen srstem und zweitem Sechstel des sagittalen Durchmessers liegt. Mit Okular- 
milzrometer ergeben sich axial bei 10 facher Linearvergrößerung folgende Verhältniswerte: Die Distanz zwischen Vorderkapsel und Katarakt verhäl sich zu der zwischen Katarakt und Hinterkapsel wie $7: 35$. Es ist also die Katarakt im axialen Gebiet doppelt so weit vom Linsenzentrum, wie vom Linsenvorderpol entfernt.

Wieder genau wie im Falle der Abb. 15 und 18 treten in der Sternfigur die Nähte (Abb. 2I) als scharfbegrenzte dunkle Jinien zutage, während die trüben Sektoren die Nahtenden in dex Faserrichtung überragen. Die Naht-

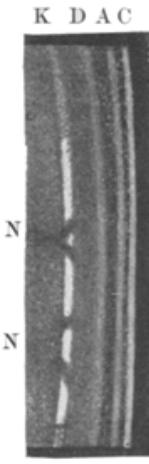

Abb. 21 a. enden bezeichnen also auch hier wieder die Incisuren zwischen den Sternstrahlen. In horizontaler Richtung beträgt der Gesamtdurchmesser dieser Trübung $4-5 \mathrm{~mm}$, in vertikaler $3-3-3 / 2 \mathrm{~mm}$. Verbreitert ist die Trübung durch den besonders langen und breiten nasalen Fortsatz B, der, wie in Abb. 16 und 18 , in glattem, zur Achse konzentrischem Bogen endigt. $0,3 \mathrm{~mm}$ nasal von diesem Bogen liegt der ebenfalls getrübte als weiße Linie markierte Kernäquator $\mathrm{N}$, dessen Bogen einem scheinbaren Gesamtdurchmesser von ca. $8 \mathrm{~mm}$ entspricht (zu diesem Durchmesser gelangte ich auch hier durch den Vergleich mit der Pupille). Die Partie zwischen dem Endbogen der Trübungspartie B und dem Kernäquator $\mathrm{X}$ ist unbedentend feinfleckig und diffus getrübt, wie überhaupt der gesante Kern eine diffuse grave, zum Teil fleckige Trübung aufweist, die da und dort von schmalen, dunklen Radiärspalten W durchsetzt ist.

Der trübe Kernäquator ist in diesem Falle in der ganzen Circumferenz zu sehen, besonders deutlich aber nasal, also im Bereiche der stärksten Trübungen. Das schmale Büschel ergibt, daß dieser Äquator und die Sterntrübung derselben Diskontinuitätsfläche zugehören. Ganz vereinzelt liegen in der dicht benachbarten Rinde feine Trübungswölkchen.

In der hinteren Kernfläche einige unbedeutende Trübungen. Die vordere Rinde weist einen Abspaltungsstreifen A und vor der Trübung einen zweiten, lichtschwachen Diskontinuitätsstreifen D auf (Abb. 2la).

Das gesunde (rechte) Auge besitzt ein kräftiges grobfirstiges Alterskernreliej, das am verletzten Auge nicht einmal in Spuren angedeutet ist! (Beobachtungsdauer ein Jahr!)

6. Beobachtung (Abb. 22-24). Das rechte Auge des 53jährigen Emil Sch., Drechsler, wurde 1892 , also vor 30 Jahren, von einer abspringenden Holzscheibe getroffen $\left.{ }^{1}\right)$. Das Auge wird von uns seit 2 Jahren an der Spaltlampe kontrolliert. $\mathrm{RS}=6 / 18 ; \mathrm{LS}=6 / 6 \mathrm{H} 1,0$. Tension normal, $\nabla \mathrm{K}$ mitteltief, Pupille erweitert sich nasal ungenügend auf Homatropin. Linse im ganzen leicht diffus trüb, bei seitlicher Beleuchtung tritt eine kräftige vordere Trubungszone (Abb. 22) her-

1) In der Krankengeschichte von 1892 ist von heftiger blutiger Lidsuggilation die Rede. Das Auge konnte nur mit Stielelevateur geöffnet werden. Außerdem bestand eine Oberlidrißwunde. Pat. wurde 14 Tage post trauma mit $\mathrm{R} S=$ $2 / 3-1$ entlassen. Von der Linse wird nichts erwähnt. Der heutige Visus beträgt rechts nur noch $6 / 18$ Glbn. Die Kontusionstrübungen prägten sich somit im vorliegenden, wie in manchen derartigen Fällen von Contusio bulbi, wohl erst längere Zeit nach dem Trauma dentlicher aus, eine Tatsache, die unfalltechnisch Beachtung verdient (vgl. auch die Beobachtung zu Abb. 3c). 
vor. Auch eine hintere Trübung ist erkennbar. Die vordere Trübung ist dicht und stellt im sagittalen Büschel eine dünne Schale dar, welche einer Diskontinuitätsfläche entsprechend verlänft, indem sie eine wesentlich stärkere Krümmung aufweist, als die Linsenoberfläche, also mit letzterer peripher divergiert (Abb. 23, $\mathrm{C}=$ Kapsel, $\mathrm{T}=$ vordere Tribungsschale). Axial beträgt die Distanz der Rosette von der Kapsel schwach $11 / 2$ Corneadurchmesser, peripher, im Bereiche der $7 \mathrm{~mm}$ weiten Pupille, etwa das doppelte.

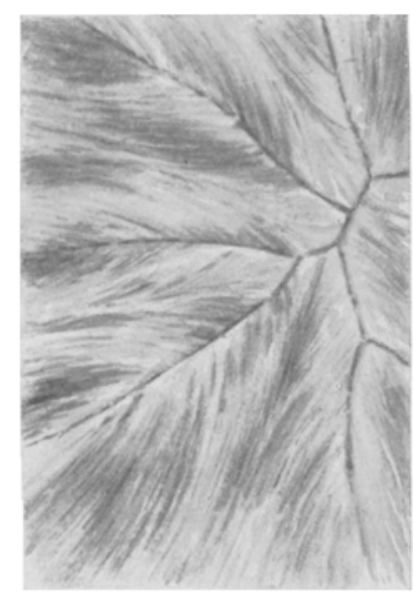

$A b b, 22$.

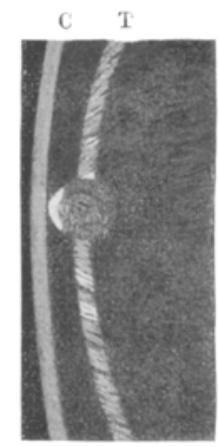

Abb. 23.

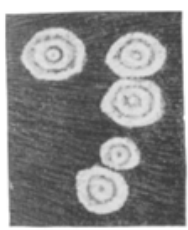

Abb. 24.

Die Rosette ist, von vornher betrachtet, vou ganz ähnlichem Typus wie die Rosetten der Abb. 15, 18 und 21. Wie in diesen Fällen, so endigen auch hier die Vordernähte in den Einschnitten der Rosette. Die Strahlen der letzteren ragen also über die Nähte hinaus und endigen stumpf, zum. Teil abgerundet. (In Abb. 22 sind die Enden nicht dargestellt. Die Abbildung stellt eine Partie der Rosette temporal und temporal unten vom Rosettenzentrum dar. Man beachte das scharfe Hervortreten des Nahtsystems und der Fasern.) Auch hier erreiehen die Strahlen den zugehörigen Äquator keineswegs, außer anscheinend nasal, wo aber die Mydriasis stets so mangelhaft bleibt, daß der zugehörige Äquator nicht sichtbar werden kann. An den übrigen Stellen ist, ganz ähnlich wie im Falle der Abb. 15 und 18, die Strecke zwisehen Rosette und zugehörigem Aquator nicht völlig trübungsfrei, sondern zeigt feine graue Punkte und Striche, die derselben Diskontinuitätszone wie die Rosette angehören. Zufolge dieser Trübungen tritt der Äquator der Trübungsschale, der wieder etwa der $8 \mathrm{~mm}$ weiten Pupille entspricht, scharf hervor. Sowohl durch die vordere Trübungsschale, als auch namentlich durch die luciden Partien hindurch ist eine hintere Trübungsschale erkennbar, welche analog wie die vordere verläuft, und welche von der Hinterkapsel durch eine klare Rindenschicht von ähnlicher Dicke wie vorn geschieden wird. Es ist im Aquatorgebiet unmittelbar festzustellen, daß vordere und hintere Trübung einer und derselben Diskontinuitätszone angehören. Im vorliegenden Falle finden 
wir ganz ahnlich wie in demjenigen der Abb. 14 (und dem der Abb. 277 des Atl. d. Splm.) feine radiärstreifige und punktförmige subkapsuläre Trübungen, die namentlich den nasalen Bereich der Linsenkapsel einnehmen. Thre Kontinuität mit der Kapsel erweisen einzelne dieser sehr zarten Trübungen wiederum dadurch, daß sie chagrinfrei sind und daher aus dem Chagrin als dunkle Linien und Streifen hervortreten. $\mathrm{Zu}$ ihnen gesellen sich weiterhin 5 runde schneeweiße Flecken von 0,2-0,3 mm Durchmesser (Abb. 24, einer der Flecken in Abb. 23), welche nasal vom vorderen Pol, im Bereiche der eben erwähnten feinstreifigen zarten Trübungen liegen und schon makroskopisch als schneeweiße Punkte hervortreten. Diese scheibenförmigen Flecken weisen eine gewisse Dicke auf, sind scharf begrenzt und zeigen eine konzentrische Schichtung, wie wir sie ähnlich etwa beim vorderen Polstar finden. Sie sind vielleicht aus Vakuolen hervorgegangen (vgl. Verf. Atl. d. Sptm. Text zu Abb. 272 u. 276).

Thre Lage ist dicht unter der Kapsel. Doch drängen sie die letztere keines. wegs ror, sie zieht vielmehr glatt iber die Flecken hinweg. Im Bereiche aller 5 Trübungen fehlt der Chagrin, doch ist jener dunkle chagrinfreie Hof nicht vorhanden, der die Kapselstare auszeichnet.

Die Gesamtdicke der Linse ist anscheinend dieselbe, wie am gesunden Auge. Jedenfalls läßt sich eine Differenz nicht sicher feststellen.

Die noch vorhandenen Subkapsulärtrübungen des vorstehenden Falles bilden einen Beleg dafür, daß die Trübungsrosette ursprünglich subkapsulär lag, und durch lucide Substanz in die Tiefe abgedrängt wurde. Einige Trübungsreste blieben mit der Kapsel in fester Ver. bindung.

Eine Abspaltungsfläche ist nur peripher schwach angedeutet. Sie ist übrigens auch am linken, gesunden Auge nur schwach ausgeprägt. Dieses letztere Auge zeigt ein deutliches Kernrelief, das rechts völlig fehlt. Die Vorderrinde dieses Auges ist axial anderthalb mal so dick wie die Hornhaut (rechts etwas weniger!), so daß wir sagen können, daß am verletzten Auge die Rosette in fast genau gleicher Tiefe liegt wie links das Alterskernrelief!

Diese Ubereinstimmung in der Tiefenlage einerseits der Katarakt, andererseits des Alterskernreliefs, ist auch hier wieder von Interesse. Nehmen wir an, daß sich seit der Verletzung, die im 23. Jahre stattfand, die Bildung neuer Rindensubstanz an beiden Augen in gleichem Maße vollzog, so könnte man zu dem Schlusse veranlaßt werden, daß das Kernrelief und damit die Alterskernoberfläche einer Linsenzone angehören, welche um das Fnde der zweiten Lebensdekade subkapsulär lag. Es würde dann das Kernrelief dieses Falles die Oberfläche der Linse darstellen, wie sie etwa bei Abschluß des Körperwachstums vorhanden war.

7. Beobachtung (Abb. 25a). In Abb. 314 des Atl. d. Splm. wurde die rechte Iris- und Linsenvorderfläche des 1874 geborenen A. F. wiedergegeben, der $1 / 2$ Jahr vorher eine Contusio bulbi dextri durch Anfliegen eines Holzstuckes erlitt. Es bestanden dort flächenhafte, dicht subkapsuläre, spinnwebige Trübungen der nasal-oberen und zum Teil auch der nasal-unteren Linsenpartien. Sie waren nur mittels Spaltlampe nachweisbar. Diese Trübungen sind heute, ca. 3 Jahre post 
trauma, ein weniges dichter geworden, zeigen deutlich streifige Form (in der Faserrichtung) und sind von der Oberfläche durch eine Schicht lucider (neugebildeter) Substanz getrennt (Abb. 25a). Die flächenhaft dünne Trübungsschicht breitet sich auch in diesem Falle, wie in den früheren, in der Richtung einer Diskontinuitätszone aus, und zwar liegt sie überall genau in der Abspaltungsfläche. Sie befindet sich daher um so entfernter von der Linsenvorderfläche, je weiter peripher (nasal) wir untersuchen (periphere Divergenz der Diskontinuitatszonen). Abb. 25a gibt die Lage der Trübung, ca. $3 \mathrm{~mm}$ nasal von der Papillenmitte, im dünnen Vertikalschnitt wieder. $(A=$ Vorderkapselzone, $\mathrm{C}=$ vordere Abspaltungsfläche mit der Trubungsschicht, welch letztere streifige Zeichnung aufaufweist.) An dieser Stelle beträgt die Distanz zwischen Trübung und Kapseloberfläche etwa halbe Hornhautdicke, axialwärts nimmt die Distanz etwas ab, peripheriewärts zu.

Es ist also an der Stelle, der die Zeichnung entspricht $(3 \mathrm{~mm}$ nasal von der Pupillenmitte), die Trübung im Laufe von 3 Jahren um Bruchteile eines Millimeters durch Apposition abgedrängt worden.

Das beidseits ziemlich gut ausgeprägte vordere Kernrelief hat nicht gelitten. Die sog. Abspaltungsfläche zeichnet sich am gesunden (linken) Auge sehr distinkt ab. Und zwar ist sie hier von der Kapsel um ein weniges weiter entfernt als am (verletzten) rechten Auge, woraus viel-

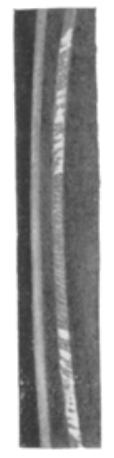

A C

Abb. 25 a. leicht auf eine gewisse Störung in der Faserapposition des verletzten Auges geschlossen werden kann.

Der vorliegende Fall lehrt, daß die Apposition einer Schicht junger Substanz von der Mächtigkeit etwa der normalerweise zwischen Kapsel und Abspaltungsfläche befindlichen im fünften Jahrzehnt einen Zeitraum von etwa drei Jahren, jedenfalls von mehreren Jahren beansprucht.

8. Beobachtung (Abb. 25b). In Abb. 183 und 184 des Atl. d. Splm. ist eine traumatisehe vordere Kapselkatarakt dargestellt, an die sich diffus wolkige Trübungen der oberflächlichen Rinde anschlieBen. Vor kurzem ist der Patient von uns wieder untersucht worden. Die Kapselkatarakt ist unverändert geblieben. Die umgebenden Trübungen sind in die Tiefe abgedrängt. Nur da und dort blieben einzelne Trübungswölkchen an der Kapsel haften (Abb. 25b, Zone A). Die Abdrängung ist etwas beträchtlicher als im vorangehenden Falle (Abb. 25b). Man beachte die vereinzelten streifigen Trübungen der Kapselzone $=\mathrm{A}, \mathrm{D}=$ Kataraktsehicht, $\mathrm{N}=$ gelbweiße Diskontinuitätszone (Alterskernzone?), $\mathrm{E}=$ vordere axiale Embryonalkatarakt. Die Verletzung (Granatexplosion) fand Anfang 1918 statt. Aufnahme von Abb. $29 \mathrm{~b}$ ungefähr 4 Jahre später.

Es können aus der Tiefenabdrängung dieser

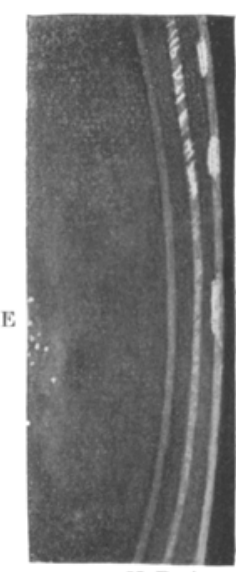

N D A

$A b b .25 \mathrm{~b}$. Trübung analoge Schlüsse gezogen werden wie im vorhergehenden Fall.

\section{Zusammenfassung der Beobachtungen über Abdrängung (Remotio) sub- kapsulärer trammatischer Tribungen zufolge Apposition junger Substanz.}

Es handelt sich in vorliegenden acht Beobachtungen um schalenförmige, durch lucide Substanz von der Kapsel abgedrängte Linsen- 
trübungen, die die Verlaufsrichtung von Diskontinuitätszonen aufweisen. Im Falle 1 und 2 ist außer dieser Trübungssehicht eine mehr oder weniger dichte, diffuse Trübung auch der zentralen Linsensubstanz vorhanden, und es ist in diesen Fällen die subkapsuläre klare Schicht wesentlich dünner als in den übrigen, trotzdem auch hier viele Jahre zwischen Verletzung und Beobachtung liegen. Offenbar sind die beiden Linsen derart schwer geschädigt, daß die Apposition neuer Substanz verzögert bzw. beeinträchtigt wird. Wie wir sehen werden, bilden solche Beobachtungen den Utbergang zu jenen, in denen zufolge noch ausgedehnterer Zerstörung eine Neubildung von lucider Substanz überhaupt ausbleibt. Auch in den übrigen sechs Fällen ist die Apposition keine gleichmäßige. Am stärksten scheint sie zu sein, wenn die Verletzung noch in die 1. bis 2. Lebensdekade fällt (Beob. 3 und 4). So erreicht die apponierte Schicht in Beobachtung 3 axial $1 / 6$ bis $1 / 7$ der Linsendicke, (Apposition zwischen 10. und 33. Jahr), in Beobachtung 4 axial $1 / 5$ bis $1 / 6$ (Apposition zwischen 17. und 52. Jahr). In Beobachtung 5, in der das Datum der Verletzung nicht genau bekannt ist, jedenfalls aber mehr denn 10 Jahre zurückreicht und in der die Apposition bis zum 45. Jahre stattfand, beträgt die apponierte Substanz etwa $1 / 6$ der Gesamtdicke. Relativ gering ist die Schichtdicke in Beobachtung 6 (Trauma vor 30 Jahren, Apposition zwischen 23. und 53. Jahr).

Interessante Aufschlüsse bringen uns Beobachtung 3 und 6 über das Alter der dem Alterskernrelief zugrunde liegenden Diskontinuitätszone. Die im Falle Sch. (Beobachtung 6) vorhandene Übereinstimmung der Rindendicke beider Linsen läßt den Wahrscheinlichkeitsschluß auf ungefähr gleiches Alter dieser Schichten zu, also auch auf gleiches Alter der sie begrenzenden Flächen, der Trübungsfläche des rechten und des Kernreliefs des linken Auges. Erstere entstand im 23. Lebensjahre, woraus wohl folgt, daß das Relief einer Schicht entspricht, die ungefähr im genannten Alter subkapsulär oder in großer Nähe der Kapsel lag. Tiefer als die Alterskernfläche am gesunden Auge liegt die Trübung bei im Kindesalter entstandenen Schädigungen. So hì Beobachtung 3, in welcher die Verletzung schon mit 10 Jahren auftrat. Hier beträgt die Dicke der klaren Schicht $1 / 6$ bis $1 / 7$ der Gesamtlinse. Am linken, gesunden Auge dagegen beträgt die Distanz zwischen Vorderkapsel und Alterskernstreifen nur 1/8 bis $1 / 9$ der Gesamtdicke, woraus wohl folgt, daß die Substanz, der die Alterskernfläche des linken Auges angehört, sich erst nach der Zeit der Verletzung des rechten Auges, somit erst nach dem 10. Lebensjahre gebildet hat.

Die mitgeteilten Beobachtungen sind natürlich noch zu spärlich, um sichere Schlüsse auf die Entstehungszeit der Fasern zu ziehen, welche die Alterskernoberfläche darstellen. Trotzdem ist vielleicht 
hier ein Weg gefunden, der in das gänzlich dunkle Gebiet der Bildung der Diskontinuitätsflächen, speziell der Alterskernflächen, wenigstens in bezug auf die zeitliche Genese einiges Licht zu bringen imstande ist.

Daß die trübe Flächenschicht in den mitgeteilten Beobachtungen tatsächlich ursprünglich subkapsulär lag, ergibt nicht nur das Studium frischer Kontusionstrübungen, sondern auch der Umstand, daß in einzelnen Fällen noch Trübungsreste fix an der Kapsel haften, wobei sie sich häufig optisch wie Kapselstare verhalten. So in den Beobachtungen 1,2 und 6 .

Was die Form der abgedrängten Trübungen betrifft, so stellen letztere meistens Rosetten dar (Beobachtung 3 bis 6 ). In den beiden Fällen sehr schwerer Schädigung mit gleichzeitiger Verringerung der gesamten sagittalen Linsendicke, die in Abb. 277 d. Atl. d. Splm. und in Abb. 14 dieser Mitteilung wiedergegeben sind, ist die Trübung eine kontinuierliche Schale, und von einer Rosette ist niehts zu erkennen. In den Fällen der $\mathrm{Abb}$. 25a und $\mathrm{b}$ lagen unregelmäßig verstreute Trübungen vor. Wo eine Rosette vorhanden ist, sitzt sie entweder nur vorn, oder aber sie setzt sich in derselben Diskontinuitätszone auch nach hinten fort, so daß eine vordere und eine hintere Trübungszone nebeneinander bestehen. Ich konnte jedoch in den mitgeteilten Fällen nie mit Sicherheit feststellen, da $B$ auch die hintere Trübung eine Rosette darstellte. - Die meist als dunkle Linien zutage tretenden Nähte erreichen mit ihren Enden fast stets gerade eben die Incisuren der Rosette, die Rosettenstrahlen dagegen reichen über diese Nahtenden hinaus. Ein gerade entgegengesetztes Verhalten fand ich bei frischen hinteren Subkapsulärrosetten traumatischen Ursprungs.

Dort folgten die Strahlen der Nahtrichtung, die Partien zwischen den Nähten bildeten die Incisuren (vgl. Abb. 202 des Atl. d. Splm., vgl. auch E. Fuchs, Wien. Klin. Wo. Nr. 3 und 4, 1888.)

Auffällig und schwer verständlich ist eine eigentümliche terminale Abrundung einzelner Strahlen (z. B. Abb. 16, 18, 21). Die Abrundung geht dem Äquator parallel.

Bald ist ferner die Rosette vollständig (Abb. 15, 21), bald partiell ausgebildet (Abb. 18). Mehrfach erreichen einer oder zwei der Rosettenstrahlen den Äquator der zugehörigen Diskontinuitätszone (Abb.16), um von da auf die Rückfläche umzubiegen. Dieses asymmetrische Verhalten der Rosette ist wohl so zu erklären, daß das Trauma nicht in axialer Richtung, sondern irgendwie schräg stattfand.

Die Dicke der Trübungsschicht ist stets sehr gering, die Intensität der Trübung ziemlich gleichmäßig. Die Faserrichtung ist im Bereiche der Trübungen meist erkennbar. Ganz feine Wölkchen sind gewöhnlich auch auf dem rosettenfreien Teil der Diskontinuitätszone nachzu- 
weisen, so in den Beobachtungen 3,5,6. Sie tragen dazu bei, den zugehörigen Aquator besonders deutlich und plastisch hervortreten $\mathrm{zu}$ lassen (Abb. 16, 18, 21). Bei partiellen Rosettenbildungen reicht dessen Sichtbarkeit im Falle von Abb. 18 nicht über die Rosette hinaus.

Daß die Trübungsschalen, im schmalen Büschel untersucht, sich der Richtung nach wie normale Diskontinuitätszonen verhalten, trat in allen Fällen, außer in demjenigen der Abb. 14 zutage, welche weiter unten noch zu erörtern ist.

\section{Messende Untersuchungen über die Tiefenlage der Alterskernoberfläche in verschiedenen Lebensaltern.}

Die vorstehenden Beobachtungen über Abdrängung von oberflächlichen Linsentrübungen nach der Tiefe, zufolge Apposition junger Linsensubstanz, führten mich in der letzten Zeit zu der Frage, ob eine derartige Abdrängung auch die Diskontinuitätszonen erleiden. Da. rauf gerichtete messende Untersuchungen ergaben, daß eine Abrïckung der Alterskernoberfläche nach der Tiefe im Laufe des Lebens stattfindet. Vergleichende Messungen an Personen des 2. bis 8. Jahrzehnts hatten zunächst das Frgebnis, daß die axiale Rindendicke (i. e. die Distanz zwischen Kapsel. und Kernpol) sowohl vorn wie hinten im Verhältnis zur Gesamtdicke der Linse mit dem Alter zunimmt. Damn aber konnte ich auch eine absolute Zunahme der Rindendicke feststellen.

Die nachstehend S. 183 mitgeteilten Vergleichswerte wurden am verschmälerten Büschel gewonnen, welches bei gerader Blickrichtung des Untersuchten in einem Winkel zur mittleren Mikroskopachse von gewöhnlich 35 Grad die Linse so durchdrang, daß die Mitte des zentralen Intervalls getroffen wurde. Das Okularmikrometer befand sich bei temporaler Lampenstellung in dem nasalen Mikroskop. Die Fehlerquelle, die sich bei dem schrägen Durchtritt durch die Divergenz (s.u.) der Discontinuitätsflächen ergibt, ist nicht groß genug, um ins Gewicht zu fallen. Eine Änderung des Einfallwinkels um $5^{\circ}$ nach der einen oder anderen Richtung ändert die Verhältniswerte nicht merklich. - Die Vergrößerungsänderung in dorsoventraler Richtung konnte ebenfalls vernachlässigt werden, nachdem sich ergeben hatte, daß die Linse sagittal durchsetzende prismatische Schlagschatten, wie sie Pigmentauflagerungen der Vorderkapsel erzeugen, ihre scheinbare Dicke bis gegen die Hinterkapsel hin nicht wesentlich änderten.

Die Bedeutung der peripheren Divergenz der (änBern) Diskontinuitätszonen wird weiter unten besprochen werden. Die durch dieselbe bedingte Fehlerquelle für unsre Messungen ist im Alter um ein weniges größer als in der Jugend, entsprechend der im Alter stärkern Divergenz der in Betracht kommenden Flächen. 
Abb. $26 \mathrm{e}$ zeigt diese Divergenz bei einem 21 jährigen, $A b b .26 \mathrm{f}$ diejenige bei einem 77 jährigen. Besonders bei Jugendlichen (z. B. im Falle Abb. 26e) verliert sich die Alterskernfläche pheripheriewärts nicht selten in einer nach dem Aquator hin an Dicke zunehmenden Zone vermehrter diffuser Reflexion (in $A b b .26$ die Zone D, vgl. auch $A b b .26 d$ ), so daß sie in dieser Zone häufig nicht mehr als Fläche unterscheidbar ist. Eine bessere Orientierung gibt in

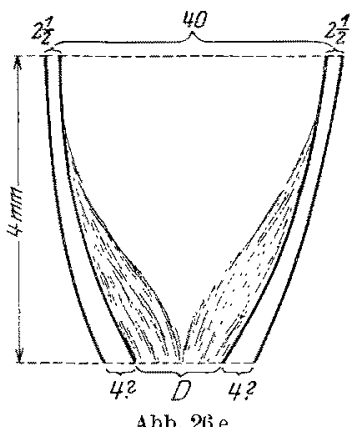

Abb. $26^{2} \mathrm{e}$.

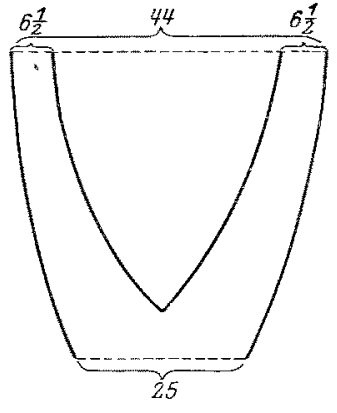

Abb. $26 \mathrm{f}$.

solchen Fällen eín spezifisch lichtstarkes, dünnes Büschel, das man möglichst schräg durchfallen läßt. - Ganz allgemein sind die Diskontinuitätszonen axial besser differenziert als peripher, insofern als eine regelmäßige Reflexion, die sich als Glanz kundgibt, hauptsächlich axial nachweisbar ist, und die Zone bier vielfach als eine einzige optische Grenzfläche imponiert (vgl, auch das fast ausschließlich axial nachweisbare Kernrelief). Dieser sprungweise Indexübergang gerade in den optisch wichtigsten, axialen Gebieten liegt zweifellos im Interesse einer regelmäßigen Brechung. In den optisch weniger in Betracht fallenden, peripheren Abschnitten ist der Ubergang ein mehr allmählicher, und die reflektierende Fläche ist durch die genannte diffus verwaschene Zone ersetzt.

In Abb. 26 b ist a $\mathrm{c}$ das Büschel. Die Schnittwerte a c, e d, do usw. werden auf die Frontale a b projiziert. Wir messen diese Projektionen (was bei 10 facher Linearvergrößerung $\mathrm{O} \mathrm{e}, \mathrm{a}_{2}$, Obj. F 55 geschieht) und ihr Verhältnis ist gleich dem gesuchten Verhältnis der Sohnittwerte. Die gewöhnliche Beleuchtungslinse wird zur Steigerung der Bildtiefe durch eine solche mit gröBerer Brennweite ersetzt. Die verwendbare fokale Strecke wird dadurch verlängert.

$\mathrm{Zu}$ derartigen Messungen gehört eine gewisse Utbung. Sie müssen sehr rasch vorgenommen

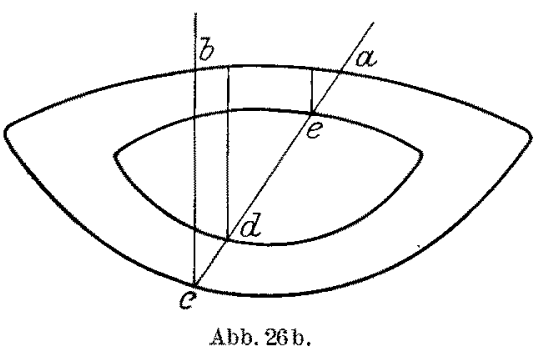

Abb. 26 b. werden, da das Objekt niemals vollkommen ruhig ist. Man hat dafür zu sorgen, daß eine bestimmte Ziffer der Skala, z. B. 0, 10, 20 auf die nasale Kante (temporale Lampenstellung) der Eintrittsbzw. Austrittsfläche des Büschels zu liegen kommt, und man vermag dann fast gleichzeitig den betreffenden Schnittwert abzulesen. Bei Ermittelung des (scheinbaren) Gesamtdickenwertes ist gleichzeitig mit der einen Hand zu fokussieren. Unmittelbar nach dem 
Ablesen kontrolliere man die veränderte Stellung. Aus einer Reihe von Messungen zieht man den Mittelwert. Man berücksichtige stets die Büscheldicke! Diese betrug bei unseren Beobachtungen durchschnittlich 0,1 mm. Hat man z. B. den Abstand der beiden Diskon-

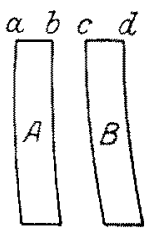

$\mathrm{Abb} .26 \mathrm{c}$. tinuitätszonen A und $\mathrm{B}$ zu messen (Abb. $26 \mathrm{c}$ ), so bestimme man die Distanz zwischen a und $\mathrm{c}$, (nicht etwa zwischen a und $d$ oder $b$ und $e$ !).

Aus einem dünnen Nitrabüschel hebt sich die Mikrometerskala weniger deutlich $a b$, wodurch die Promptheit der Ablesung erschwert wird. Bei Jugendlichen ist die durch die Büschelverdünnung bedingte Lichtschwäche wesentlich größer als bei Greisen, zufolge der geringeren inneren Linsenreflexion in der Jugend gegenüber derjenigen im Alter. Die Deutlichkeit der Skala (bei konstanter Büscheldicke) stellt so einen Indicator für die Intensität der inneren Linsenreflexion dar. Zu beachten ist, daß die Alterskernzone vor der Pubertätszeit meist

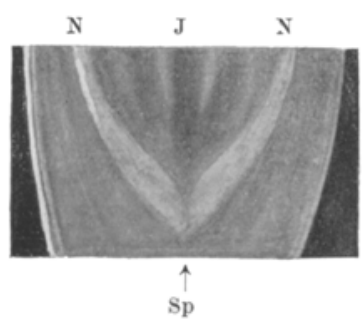

Abb. $26 \mathrm{a}$. sehr lichtschwach und nicht sicher von anderen Diskontinuitätszonen zu unterscheiden ist.

Beispiel (Fall Abb. 26d). 53jähriger J. Sch., $\mathrm{N}=$ Alterskernzone, peripher sich verdickend, äquatorial durch Einschiebung des zentralen Intervalls $=J$, zum Teil gespalten $=$ Sp: Für das Gesamtbüschel (Strecke a c, Abb. 26b) ergibt sich der Wert 41, für die vordere axiale Rinde der Wert 7,5. Die axiale Rinde mißt somit $7,5 / 41=0,18$ der Gesamtdicke. Auf den Kern entfällt der Wert 0,64, da vordere und hintere Rinde dieselbe Dicke aufweisen.

Die in den Stäben der Tabelle enthaltenen Dezimalen beziehen sich also auf eine Gesamtdicke $=1$. Die Alterskernzone weist im vorstehenden Beispiel eine namhafte Dicke anf, und zwar auch axial. In solchen Fällen wurde die der Rinde zugewandte Fläche als Kernrindengrenze angenommen.

Die Beobachtung der in der Tabelle mitgeteilten Fälle geschah meist bei Homatropin-Cocain-Mydriasis, zum Teil auch bei Cocainmydxiasis oder ohne solche ${ }^{1}$ ). Außer der axialen Rindendicke sind gleichzeitig noch einige andere Maße notiert. So z. B. die Kerndicke, die zum Teil direkt gemessen, zum Teil durch Subtraktion der Pindendicken vom Gesamtwert berechnet wurde.

$\Delta=$ axiale Distanz zwischen Vorderkapsel und vorderer Alterskernoberfläche (vordere axiale Rindendicke).

$\mathrm{P}=$ Distanz zwischen Hinterkapsel und hinterer Alterskernfläche (hintere axiale Rindendicke).

$\mathrm{E}=$ axialer Abstand der äußeren vorderen Embryonalkernzone von der Vorderkapsel.

1) Soweit vorlänfige Untersuchungen ergeben, ändert das Mydriatioum an den Dickenverhältnissen nichts, was im Hinblick darauf, daß der Cntersuehte nicht akkomodiert, verständlich ist. Unsre Versuche, die Zunahme der Linsendicke bei der Akkommodation zu ermitteln, hatten übrigens bisher ein negatives Resultat. 
$\mathrm{K}=$ axialer Abstand der vorderen axialen Embryonalkatarakt von der Vorderkapsel.

$\mathrm{N}=$ axiale Kerndicke. kapsel.

$\mathrm{C}=$ Distanz der hinteren (inneren) Embryonalnaht $(\lambda-\mathrm{Nah} t)$ von der Hinter-

\begin{tabular}{|c|c|c|c|c|c|c|c|c|c|c|c|c|c|c|c|}
\hline Name & Jahre & A & $P$ & $\mathbf{E}$ & $\mathbf{K}$ & N & $\mathrm{c}$ & Name & Jahre & A & $p$ & E & $\mathrm{K}$ & $N$ & o \\
\hline J. W. O & 12 & 0,08 & 0.08 & 0.18 & & 0.84 & & R. J. O & 40 & 0,125 & & & 0,37 & 0,7 & 0,375 \\
\hline W. F. $\sigma^{\pi}$ & 13 & 0,078 & & & & 0,84 & & F. P. & 40 & 0,14 & 0,15 & & & $0,71 \mid$ & 0,45 \\
\hline M. S. 우 & 14 & 0,056 & & & & 0,88 & & O. R. $\frac{\text { O }}{9}$ & 41 & 0,11 & & (Cat & $\operatorname{cor}$ & onar.) & \\
\hline S. R. 웅 & 15 & & & unsic & cher & & & Ch. M. & 42 & 0,14 & & & & $\mid 0,84$ & 0,38 \\
\hline Sp. A. $\sigma^{\pi}$ & 17 & 0,666 & & & & 0,86 & $\mid 0,36$ & R. G. & 43 & 0,12 & 0,13 & & & 0,75 & 0,44 \\
\hline Sp. R. 오 & 18 & 0,09 & & & 0,34 & 0.81 & & B. A & 45 & 0,17 & & & & 0,66 & \\
\hline Seh. W. $0^{*}$ & 18 & 0,078 & & & & 0,84 & & A. $R$. & 46 & 0,146 & & & & 0,68 & \\
\hline Sd. M. Q & $191 / 2$ & 0,09 & & & & 0,81 & & 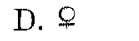 & 47 & 0,11 & & & & 0,74 & \\
\hline $\mathrm{Sd} . \mathrm{E} . \mathrm{O}$ & 21 & 0,107 & & & & 0,79 & 0,36 & St. $\sigma^{\top}$ & 50 & 0,14 & & & & 0,72 & \\
\hline Sch. H. 우 & 23 & 0,08 & & & & 0.84 & & W. M. $\stackrel{\text { O }}{2}$ & 52 & 0,14 & & & & 0,66 & \\
\hline G. D. 우 & 24 & 0,09 & & & 0,28 & 0,81 & & Sch. J. $\sigma^{\pi}$ & 53 & 0,18 & & & & 0,64 & \\
\hline E. M. $\frac{\mathrm{C}}{}$ & 25 & 0,11 & & 0,16 & & 0,74 & & M. A. $\sigma^{\pi}$ & 58 & 0,18 & 0,18 & & & 064 & \\
\hline A. ㅂ. 우 & 26 & 0,11 & & & & 0,77 & & K. A. o & 61 & 0,166 & & & & 0,66 & \\
\hline W. E. 우 & 27 & 0,09 & 0,08 & & & 0,82 & & M. B. $\sigma^{7}$ & 65 & 0,175 & 0,162 & & & 0,67 & \\
\hline E. K. $\mathrm{P}$ & $28 \%$ & 0,1 & 0,1 & & & 0,8 & & N. $\mathrm{Q}$ & 67 & 0,175 & & & & 0,65 & \\
\hline L. K. $\mathrm{O}$ & 31 & & isiche & $r(\mathrm{Ca}$ & at. c & ronar. & & K. $\sigma^{x}$ & 69 & 0,186 & & & & 0,6 & \\
\hline R. K. o & 33 & 0,09 & & & & 0,8 & 0,4 & K. K. & 70 & 0,18 & 0,21 & & & 0,59 & 0,4 \\
\hline P. F. O & 35 & 0,106 & & & & 0,75 & & W. G. & 77 & 0,20 & 0,19 & & & 0,62 & \\
\hline $\mathrm{Sd} .3^{\pi}$ & 38 & 0,17 & & & & 0,68 & & & & & & & & & \\
\hline
\end{tabular}

Aus der mitgeteilten Tabelle ist ersichtlich, daß die axiale Distanz zwischen Vorderkapsel und Alterskernoberfläche (axiale Rindendicke) am Ende der zweiten und in der dritten Dekade einen wesentlich kleineren Abschnitt der gesamten Linsendicke einnimmt, als in den folgenden Dekaden, und daß diese axiale Rindendicke (sowohl die vordere wie die hintere) bis ins hohe Alter zunimmt. Beträgt sie z. B. in der Mitte der zweiten Dekade 1/14, in der dritten $1 / 10$ der Gesamtdicke, so ist sie in der achten auf $1 / 5$ der letzteren gestiegen!

Gleichzeitig hat sich die Kerndicke $(N)$ im Verhälinisse zur Gesamtdicke verringert. Sie beträgt in der zweiten Dekade über $1 / 5$, im 70 . bis 80. Jahr dagegen nur noch etwa $2 / 3$ der Gesamtdicke!

Den einzelnen Altersstufen geht sowohl die relative Zunahme der Rindendicke, als auch die relative Abnahme der Kerndicke parallel, wobei nicht größere Unregelmäßigkeiten vorzukommen scheinen, als wir sie bei anderen physiologischen Altersveränderungen anzutreffen pflegen.

Es ist also erwiesen, daß die Alterskerndicke nach Abschlu $\beta$ des Körperwachstums im Verhältnis zur Gesamtdicke der Linse fortschreitend abnimmi, während die Rindendicke wächst.

Ich konnte in diesen vergleichenden Untersuchungen außerdem zeigen, daß die Dickenzunahme der Rinde nicht nur eine relative, sondern 
auch eine absolute ist. Dieser Nachweis. geschieht durch Vergleich mit der Hornhautdicke, welche nach unseren Beobachtungen nach Absehluß des Wachstums als konstant oder doch annähernd konstant gelten kann. Erreicht die Rindendicke in der Jugend kaum die Hornhautdicke, so beträgt sie im höheren Alter das zwei- bis dreifache derselben. Wiederum bilden die dazwischenliegenden Altersabschnitte Ubergangsstufen.

Die hier gefundenen Tatsachen mögen auf den ersten Blick paradox erscheinen. Hat man sich doch durch anatomische Beobachtungen und durch die Erfahrungen der Staroperation an die Vorstellung von einem Dicker- und Größerwerden des „Kerns" mit fortschreitendem Alter gewöhnt. Es ist eine feststehende Tatsache, daß im höheren Alter die Sklerose bis unter die Kapsel reichen kann, so daß sich nach Zerreißen der letzteren die Linse kompakt und in toto entfernen läßt. Eine andere Frage ist jedoch die, was wir unter ,:Alterskern" zu verstehen haben.

Wie die obigen Untersuchungen zeigen, ist er nicht mit dem von der Staroperation her geläufigen Begriff „Kern" identisch. Als Alterskern hat vielmehr die von der kräftig reflektierenden Alterskernfläche umschlossene, mit der Spaltlampe von der Pubertätszeit an das ganze Leben hindurch verfolgbare Linsenpartie zu gelten. Fassen wir unrichtigerweise, wie das heute zu geschehen pflegt, den „Kern" als identisch mit der sklerotischen Linsensubstanz auf, so sind wir gezwungen, in den Fällen von Totalsklerose die ganze Linse als ,Kern" zu bezeichnen!

Erinnern wir uns dieser unhaltbaren Auffassung gegenüber an die von Freytag $\left.{ }^{1}\right)$ nachgewiesene Tatsache, daß Indexerhöhung und Sklerosierung in weitem Maße voneinander unabhängig sind. Es bestehen in der vollkommen weichen, in bezug auf die Konsistenz scheinbar homogenen Neugebornen- und Fötenlinse fast ebenso große Indexdifferenzen (zwischen Linsenzentrum und Rinde), als sie im Alter zwisehen Rinde und sklerotischem Kernzentrum vorhanden sind! $J a$, die Indexdifferenz zwischen Zentrum und Rinde der völlig weichen Neugebornenlinse ist wesentlich größer, als diejenige zwischen dem Linsenzentrum eines Neugebornen und demjenigen eines 80jährigen!

Die Alterskernfläche ist aber nichts anderes, als die Grenafläche zwischen. zwei Medien von verschiedenem Index. Sie reflektiert, sie spiegelt, und zwar auch noch im hohen Alter, zu einer Zeit, zu welcher die Sklerose die Rinde bereits ergriffen, also die spiegelnde Grenzfläche überschritten

1) Gustav Freytag, Die Brechungsindices der Linse und der flüssigen Angen. medien des Menschen und höherer Tiere in verschiedenen Lebensaltern in vergleichenden Untersuchungen. Habilitationssehrift J. F. Bergmann, Wiesbaden 1908. S. 58 . 
hat! In diesem optischen Sinne sprechen wir von einem Alterskern, der sich, wie hier gezeigt wurde, mit fortschreitendem Alter mehr und mehr dureh Apposition junger Fasersubstanz, also durch Rindenverdickung von der Kapsel entfernt.

Die vorstehenden Beobachtungen einer Abdrängung der Alterskernfläche nach der Tiefe zu reihen sich somit an die Beobachtungen über Abdrängung traumatischer Flächentrübungen von der Kapsel weg - an. Hier wie dort Zunahme der Abdrängung mit steigendem Alter, gleichzeitig auch Zunahme der peripheren Divergenz (s. u.) oberflächlicherer und tieferer Zonen, entsprechend der flacheren Form der ersteren. Letztere Zunahme veranschaulichen die Zeichnungen 26 e und f. $26 \mathrm{e}$ gibt die Verhältnisse bei einem 21 jährigen, Abb. $26 \mathrm{f}$ bei einem 77 Jährigen wieder.

Aus der Tabelle ist ersichtlich, daß bei Cataracta coronaria der Nachweis der Alterskernzone nicht immer gelang, anscheinend wegen der Lichtschwäche der letzteren. Die Ursache bilden nicht etwa Trübungen. Im Gegenteil, die axialen Linsenpartien können von solchen ganz frei sein. Am ehesten noch war die Zone durch Einstellung des Spiegelbezirkes erhältlich.

\section{Unbegrenztes Linsenwachstum als Ursache der Abdrängung ursprünglich subkapsulärer traumatischer Trübungen.}

Die oben mitgeteilten Krankengeschichten von flächenhafter traumatischer Katarakt leisten zum erstenmal den Nachweis, daß beim Menschen, wie dies experimentell beim Tier schon lange festgestellt ist (z. B. Leber 1880, E. v. Hippel 1905, und 1907, ferner Verf. Atl. d. Splm. S. 117), ursprünglich subkapsuläre traumatische Trübungen dureh das Linsenwachstum von der Kapsel weg nach der Tiefe abgedrängt werden, wobei diese Abdrängung eine um so größere ist, je längere Zeit seit dem Trauma verstrich. Ganz besonders geht aber aus den vorstehenden Beobachtungen hervor, daß auch noch nach Abschlu $\beta$ des normalen Körperwachstums die Produktion neuer Linsenfasern fortbesteht, daß also die menschliche Linse während des späteren Lebens kontinuierlich weiter wächst. In diesem ununterbrochenen Wachstum der Linse besteht eine Utbereinstimmung mit dem Wachstumscharakter anderer epidermoidaler Gebilde, der Epidermis, der Nägel, der Haare, der Zähne. Auch bei letzteren ein unbegrenztes Wachstum während des ganzen Lebens, das zu monströser, die Funktion störender Ausdehnung führen müßte, wenn ihm nicht die natürliche Abnützung (bei den Haaren der physiologische Wechsel) kompensierend gegenüber stände. Dadurch gelangen gerade die älteren, stärker verbrauchten Elemente zur Ausscheidung.

Auch an der Linse müßte die unbeschränkt fortdauernde Appo- 
sition schließlich zu einem Volumen führen, das sich mit der Tätigkeit und dem verfügbaren Raum nicht mehr vertragen würde, wenn nicht hier eine besondere Reguliervorrichtung der Vergrößerung Schranken setzte: Es besteht ditse Reguliervorrichtung in der Verdichtung (Sklerose) der Linse.

Die Eliminierung der überschüssigen Zellelemente durch Abstoßung in die Außenwelt, wie sie bei den erwähnten Epidermoidalgebilden stattfindet, ist an der Linse aus naheliegenden Gründen ausgeschlossen. Das Problem der Volumverminderung wird aber dadurch gelöst, daß nicht die Elemente selber, nur das in ihnen enthaltene Wasser der Ausscheidung verfällt, daß also durch Eindickung der Faserelemente und zwar auch hier der älteren (,verbrauchten “) Fasern das Volumen auf das notwendige Maß zurückgeführt wird. Wir gelangen also auf Grund unserer obigen Beobachtungen zu dem zwingenden Schluß, daß ein direkter Kausalkonnex zwischen unbeschränkter Apposition neuer Linsensubstanz und physiologischer Linsensklerose besteht.

Zu denselben Schlüssen ist auf anderem Wege schon Priestley Smith (Brit. Med. Journ. I 1883, S.112) gelangt. Priestley Smith zog die obenstehenden Folgerungen aus seinen Wägungen und Messungen von Linsen verschiedener Lebensalter. Er fand eine bis ins hohe Alter langsam ansteigende Zunahme sowohl des Gewichtes als auch des Volumens der Linse. Nach Priestley Smith kann diese Zunahme nur durch eine fortschreitende Apposition neuer Substanz erklärt werden. Der Smithsche Schluß ist allerdings nicht vollkommen zwingend. Denn auch eine Wasseraufnahme in die Linse, wie sie tatsächlich im Alter wahrscheinlich gemacht worden ist, könnte Volumen und Gewicht erhöhen. Dagegen könnte eine solche die Abdrängung trüber Substanz nicht erklären.

Das Problem der Linsensklerose und damit der Presbyopie bot von. jeher der teleologischen Betrachtungsweise besondere Schwierigkeiten. Setzt doch die Sklerose schon im Präsenium, bei Hypermetropen noch früher, die Brauchbarkeit des Auges in unerwünschter Weise herab. Heute dürfen wir die genannte Wachstumseigentümlichkeit letzten Endes als die Ursache der Presbyopie betrachten.

Welchen Faktoren allerdings die GesetzmäBigkeit entspringt, mit der die beiden entgegengesetzten Vorgänge: Apposition junger und Verdichtung alter Fasersubstanz gerade soweit sich das Gleichgewicht halten, daß ein bis zu einem gewissen Grade konstantes Gesamtvolumen der Linse resultiert, ist ebenso unbekannt, wie wir nichts über die Faktoren wissen, welche alles organische Wachstum auf Grund vererbter Anlagen des Individiums, der Rasse und der Art zeitlich und räumlich in Grenzen halten. 


\section{Die pheriphere Divergenz der Diskontinuitätsflächen als Ausdruck einer physiologiseh fortschreitenden Linsenabplattung.}

Die Messungen Freytags (1. c.) mit dem Abbeschen Refraktometer, die als besonders einwandfrei zu gelten haben, ergeben einen Brechungsindex der Rinde von 1,387 ((vorderer Pol) bis 1,385 (hinterer Pol) und einen solchen der äquatorialen Rinde von 1,375. Es geht also aus diesen Messungen mit Wahrscheinlichkeit hervor, daß die Rinde wasserreicher ist am Äquator als an den Polen ${ }^{1}$ ).

Als besonders bemerkenswertes Resultat dieser und auch früherer Untersuchungen darf gelten, $d a \beta$ es eine optische Homogenität auch der jugendlichen Linse nicht gibt. Sehon beim Foetus und beim Neugeborenen besteht vielmehr eine beträchtliche Indexdifferenz zwischen Rinde und Zentrum, indem als Index des letzteren beim Neugeborenen 1,4026, beim Greise 1,4094 zu gelten hat. Gullstrand nimmt auf Grund dieser Befunde als Index der Linse 1,386, als solchen der ,äquivalenten Kernlinse" 1,406 an. Die Indexerhöhung des Zentrums an sich braucht noch keine Erhöhung des Gesamtindex zur Folge zu haben. Die Gestalt der Grenzfläche der Zone mit erhöhtem Index ist für den Gesamt. effekt entscheidend. Diese ist aber, wie wir heute wissen, und wie zum ersten Mal die Spaltlampe am lebenden Auge veranschaulichte (Verf. Atl. d. Splm. Abb. 100b) durch Diskontinuitätszonen gegeben, deren Krümmungsradius kleiner ist als der der Linsenoberfläche. Dadurch ist eine Steigerung des Gesamtindex gewährleistet.

Die bisherige Anschauung, da $B$ die Indizialkurve der menschlichen Linse im Laufe des Lebens eine Änderung im Sinne eines mehr sprungweisen Ansteigens im Bereiche einer einzigen Diskontinuitätszone erfahre, erscheint nach unseren Spaltlampenbefunden nicht mehr haltbar. Wir konnten, statt der bisher angenommenen einen (vorderen und hinteren) eine Reihe von Diskontinuitätszonen feststellen. Untersuchten wir letztere in der Weise, daß der Krümmungsradius der beobachteten Stelle mit Einfalls- und Beobachterrichtung gleiche und in derselben Ebene liegende Winkel bildete, so ergab sich ein Maxi-

1) Freytag pflegte die Linsenproben mit einem Löffelchen zu entnehmen. Da nun, wie unsere Spaltlampenuntersuchungen ergeben, die Diskontinuitätszonen der äußeren Linsenschichten axial wesentlich näher beieinander liegen als äquatorial, so folgt, daß mit der Freytagschen Methode axial und äquatorial nicht gleichwertiges Material geholt werden konnte. Am Pol mußten tiefere Zonen mitkommen als am Äquator. Es geht also aus den Freytagschen Untersuchungen nicht hervor, daß ein und dieselbe Zone axial und äquatorial einen verschiedenen Index aufwies. Es ist daher die Annahme Mathiessens, daß die oberflächlichste Schicht der Linse an allen Stellen gleichbrechend sei, noch nicht, wie Freytag annimmt, widerlegt (Freytag 1. c. S. 43), und es sind auch die anderen Deduktionen Freytags unter den hier gegebenen neuen Gesichtspunkten zu beurteilen. 
mum der Reflexion, die oft durch einen deutlichen Glanz zum Ausdruck kam. Diese Eigenschaft beweist das Torkandensein von Diskontinuitätsflächen. Solche Flächen lassen sich mit der Spaltlampe in beliebigem Alter nachweisen, wodurch wiederum die Unzulänglichkeit der bisherigen Anschauungen, die auf anderem. Wege gewonnen waren, zu Tage tritt.

Auch schon an Linsen von frischen Föten, die ich der Güte des Herrn P. D. Dr. P. Hiussy verdanke, konnte ich mehrere Diskontinuitätsflächen feststellen.

Es folgt aus diesen Befunden, da B in der Linse jeder Altersstufe Bezirke verschiedenen Indicis sich nachweisen lassen und daß diese Bezirke nicht allmählich, sondern mehr sprungweise ineinander übergehen, so daß die optische Heterogenität der Linse künftig von diesen neuen Beobachtungen aus zu bewerten sein wird. Hatte man aus den Kernbildchen schon in bezug auf die Zahl der Diskontinuitätszonen irrige Schlüsse gezogen, so war es nach der erwähnten Methode noch viel weniger möglich, etwas sicheres über die nähere Beschaffenheit, insbesondere über die genauere Verlaufsrichtung der Zonen auszusagen. Heute liegen die Flächen unmittelbar vor uns und können mit dem Spaltbüschel Punkt für Punkt abgetastet werden. Dabei ist eine periphere Divergenz aller oberflächlicheren Diskontinuitätszonen schon makroskopisch ohne weiteres erkennbar ${ }^{1}$ ), sowohl an der in situ befindlichen, als an dex herausgenommenen Linse.

Das Verhalten der Zonen nach Verlaufsrichtung, sowie auch nach Dickenausdehnung, wie es sich im stark verschmälerten Nitra- und Mikrobogenbüschel darstellt, soll hier kurz erörtert werden.

Unter Diskontinuitätszone darf nicht eine einzige Trennungsfläche im optischen Sinne verstanden werden. Die Zonen, die uns als Reflexmaxima imponieren, besitzen vielmehr eine gewisse Dicke, worunter wir ihre sagittale (oder, vom Linsenzentrum aus betrachtet, radiäre) Ausdehnung verstehen, wie sie bei meridionaler Durchleuchtung zlitage tritt. Häufig ist schon makroskopisch erkennbar, daß diese Dicke keine einheitliche ist, und daß sie in jeder Zone sukzessive von der Axe nach der Peripherie sich ändert. Eine Verdickung nach der P€ripherie hin ist $\mathrm{z}$. B. im Bereiche der Alterskernzone konstant nachweisbar (vgl. Abb. 26a, bei s. und Abb. 26d, N Alterskernzone, vgl. auch S. 181). Gelegentlich gelingt es, im peripheren $\mathrm{Ab}$ schnitt dieser Zone 2 oder mehrere Maxima zu exkennen, welche, wie die Zonen selber, unter sich peripheriewärts divergieren ${ }^{2}$ ). Diese

1) Bei derartigen Beobachtungen stellten wir wiederholt fest, daß (irregulärer) Hornhantastigmatismus Verbiegungen der Diskontinuitätszonen vortäuscht.

2) Wie Abb. 26d zeigt, schiebt sich in den äquatorialen Teil der Alterskernzone das (locide) zentrale Intervall $J$ ein, ein nicht seltener Befund. Es ent- 
periphere Divergenz ist, wie wir sehen werden, ganz allgemein der Ausdruck einer Linsenabplattung in sagittaler Richtung, welche $\mathrm{Ab}$ plattung somit in der Alterskernzone ganz besonders kräftig zum Ausdruck gelangt.

In bezug auf die Dickenänderung verhalten sich die verschiedenen Zonen nicht gleich. Und zwar nehmen die das zentrale Intervall vorn und hinten begrenzenden Embryonalkernzonen (Abb. 26a E $\mathrm{E}^{\prime}$ ) eine Ausnahmestellung ein. Sie sind axial am dicksten, während für alle übrigen Zonen das Umgekehrte gilt.

Nun die Verlauffsichtung. Sie ist in Abb. 26a, wie sie am Auge des Erwachsenen sehon makroskopisch erkennbar ist (verschmälertes Büschel und spezifisch helle Lichtquelle vorausgesetzt!), dargestellt. Man beachte die periphere Divergenz aller, mit Ausnahme der bereits erwähnten zentralen Zonen. Nur in letzterem, ältestem Teil der fötalen Linse kommt eine Divergenz nicht zum Ausdruck. Hier bilden zentrales Intervall und vorderer und hinterer Embryonalkernstreifen $\mathrm{E}$ und $\mathrm{E}_{\mathbf{1}}$ eine kaffeebohnenähnliche Figur, die an jeder normalen Linse in charakteristischer Weise erkennbar ist. Die Konfiguration des Zentrums ist somit durch die konkavkonvexe Gestalt der embryonalen Diskontinuitätszonen bedingt ${ }^{1}$ ).

Auf diese Embryonalkernzonen $\mathrm{E}$ und $\mathrm{E}_{1}$

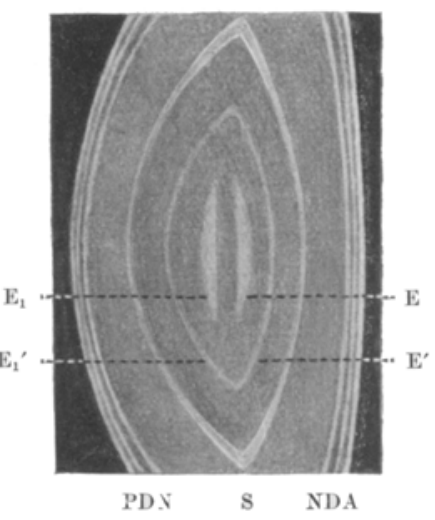

Abb. 26 a. folgt vorn wie hinten eine stärker gewölbte Zone (vorn $E^{\prime}$, hinten $E_{1}{ }^{\prime}$ ), so daß von einer peripheren Konvergenz der das Zentrum umgebenden Zonen gesprochen werden kann, indem peripheriewärts $\mathrm{E}$ sich $\mathrm{E}^{\prime}$, $\mathrm{E}_{1}$ sich $\mathrm{E}_{1}^{\prime}$ nähert.

Vielleicht dürfen wir sowohl in dieser Konvergenz, als auch in der konkarkonvexen Form der Embryonalkerzonen (Abb. 26a) den Ausdruck für ein stärkeres Dickenwachstum der Linse in früher embryonaler Zeit erblicken. Machen wir nämlich die nicht unwahrscheinliche Annahme, daß die konvexen Oberflächen aller Zonen, also auch der Embryonalkernzonen, in einem bestimmten Lebensabschnitt substeht dadurch eine Art Spaltung (Sp). $\mathrm{N}=$ Alterskernzone (vgl, ferner S. 182).

1) Nach den vorliegenden Messungen ist der Index im Kernzentrum am größten und nimmt nach der Peripherie ab (vgl. z. B. Freytag l. e.). Daraus, daß die hintere embryonale Diskontinuitätszone stets wesentlich lebhafter reflektiert, als die vordere (Verf. Atl. d. Splm. Abb. 125), darf wohl geschlossen werden, da.B die Indexänderung in homologen vorderen und hinteren Embryonalkerngebiet keine identische ist. 
kapsulär lagen ${ }^{1}$ ), in einer späteren Zeit dagegen die Zonen $\mathrm{E}^{\prime}$ und $\mathrm{E}_{1}^{\prime}$, so ergibt sich für den zwisehenliegenden Zeitabsehnitt ein relativ starkes Dickenwachstum, eine vermehrte Volumzunahme in sagittaler Richtung. Alle übrigen, also die außerhalb dieses zentralen $\mathrm{Ab}$ schnittes gelegenen Diskontinuitätszonen zeigen das Symptom der peripheren Divergenz (Abb. 26a. A. D. N. S.).

Aus Abb. 26a, welche die Verhältnisse bei einem 7ojährigen wiedergibt, ist ohne weiteres erkennbar, daß Zone $S$ einen gröBeren Radius besitzt als Zone $\mathrm{E}^{\prime}$, Zone $\mathbf{N}$ einen größeren als $\mathrm{S}$ nsw., während der gröBte Radius der Kapselobertläche A zukommt.

Die Einzelzonen divergieren also nach dem Äquator hin, und wenn wir uns erinnern, daB mit großer Wahrscheinlichkeit jede dieser Zonen einmal dicht unter d:r Kapsel lag, also für einen bestimmten Zeitpunkt die äußere Form der Linse repräsentierte, so veranschaulicht uns die periphere Divergenz eine fortschreitende Abplatiung der Linse. Die Divergenz bleibt das ganze Leben hindurch gewissermaßen der graphische Ausdruck für diese Abplattung.

Eine im Laufe des Lebens fortschreitende, dorsoventrale Abplattung wurde schon von früheren Autoren auf anderem Wege, nämlich durch Messungen von Leichenlinsen wahrscheinlich gemacht.

Derartigen Messungen an meist herausgenommenen oder doch nicht mehr frischen Leichenlinsen hafteten allerdings große Fehlerquellen an, und es differieren daher auch die Ergebmisse der einzelnen Autoren. Daß aber die Linse des Neugeborenen nahezu kugelig, die des Greises dorsoventral stark abgeplattet ist (der äquatoriale Durchmesser dürfte den sagittalen gewöhnlich um nahezu das Doppelte ïbertreffen), darüber besteht wohl kein Zweifel ${ }^{2}$ ).

Die im Laufe des Lebens auftretende Abplattung läßt sich, wie von uns früher gezeigt wurde (Verf. Atl. d. Splm. Abb. 128), entwickelungsmechanisch als eine Funktion des Nahtsystems darstellen. Nimmt man ein gleichmäßiges Querschnittvolumen auf der ganzen Strecke einer Faser an, so muß eine stärkere Ausbildung des Nahtsystems, also eine Verlängerung der gesamten Nahtstrecke, notwendigerweise eine Abplattung der Linse in dorsoventraler Richtung zur Folge haben. Da nämlich jede Faser eine vordere und eine hintere Naht verbindet

1) Diese Annahme, daß jede Diskontinuitätszone in ihrer ganzen Ausdehnung einmal subkapsulär lag, also die Oberfläche der Linse bildete, erscheint durch die oben mitgeteilten Beobachtungen über Verlagerung traumatischer Trübungen nach der Tiefe wenigstens fïr die oberflächlicheren Zonen hinreichend erwiesen. Wir sahen, daß diese trüben Zonen sich in bezug auf ihren Verlauf wie Diskontinuitätszonen verhalten, bzw. mit solchen zusammenfallen.

2) Vgl. auch die Beobachtungen von Petit (1730), die ophthalmometrischen Messungen von Bertrin-Sans bei Tieren (1893), die Untersuchungen von Holth (1899) usw. 
und da die Fasern lückenlos nebeneinander liegen, so bedingt die Verlängerung der Nahtstrecken eine Abplattung der Faserenden und damit eine Verdünnung in radiärer (sagittaler) Richtung. Anders aus. gedrückt: Die Fasern im Äquatorgebiet müssen eine um so größere radiäre Dicke aufweisen, auf je engerem Bezirk sie zusammengedrängt sind, i. e. je kürzer die Äquatoriallinie im Vergleiche zur Nahtstrecke ist.

Dieser Zusammenhang zwischen Ausbildung des Nahtsystems und Abplattung läBt sich nicht nur am Menschen ontogenetisch verfolgen, sondern er zeigt sich auch in der Stammesgeschichte. Wenigstens besitzen die Linsen der Nager und mancher Raubtiere mit ihrer unverzweigten linearen Naht eine wesentlich rundlichere Form, als die der Primaten und des Menschen mit ihrem viel stärker ausgebildeten Nahtsystem ${ }^{1}$ ).

Wäre das Nahtsystem der abgeplatteten menschlichen Linse kurz, etwa unverzweigt linear, wie dasjenige des Kaninchens, so müßte das Querschnittvolumen der Faser sich nach den Enden hin entsprechend verjüngen. Denn es verhält sich die Breite der Faser im Äquator zu derjenigen am Nahtansatze (also zum Faserende), wie die Äquatoriallinie zur doppelten Nahtstrecke. Die doppelte Nahtstrecke ist aber im genannten Falle wesentlich kürzer als die Äquatoriallinie. Damit eine Linsenabplattung möglich wäre, müßte sich die Faser außerdem. in ihrer (radiären) Dicke terminal entsprechend verjüngen, Es müßte also eine Faser von großer Dicke im Äquatorialbereich und spitz auslaufenden Enden resultieren, wie sie beim Menschen nicht vorkommt. Auch diese Überlegung zeigt somit, daß die stärkere Ausbildung des Nahtsystems bei gleichmäßigem Querschnittvolumen der Faser eine Verringerung der Linsendicke in dorsoventraler Richtung zur Folge hat.

Zusammenfassend können wir sagen, daß die periphere Divergenz der Diskontinuitätsflächen uns die fortschreitende Linsenabplattung vor Augen führt, welche entwicklungsmechanisch durch eine Verlängerung der Nahtstrecken erreicht wird ${ }^{2}$ ).

1) Rabl (Über den Bau und die Entwicklung der Linse, Leipzig 1900), dem wir die ersten genaueren vergleichend anatomischen Untersuchungen über die Linse verdanken, bemerkt (S. 214): „Die Linsen des Menschen sind die flachsten von allen. Es gibt ja immerhin Säugetierlinsen, die vorn noch mehr abgeflacht sind als sie, aber nirgends ist die Wölbung beider Flächen so gering, wie bei ihnen." Der Entwicklung des Nahtsystems hat Rabl noch wenig Beachtung geschenkt. In bezug auf das Nahtsystem der erwachsenen Menschen erwähnt er eine Mehrstrahligkeit (es sollten 9 Strahlen sein). Beim Foetus und Neugeborenen sah er 3 Strahlen, über deren genauere Form und Anordnung er nichts bemerkt.

$\left.{ }^{2}\right)$ Nicht eine Abplattung, wohl aber eine periphere Divergenz der Diskontinuitätszonen könnte auch noch durch schrumpfung, und zwar durch ungleichmäßige, der von den verschiedenen Diskontinuitätszonen umschlossenen Linsenpartien zustande kommen. Die Schrumpfung müßte nämlich in äquatorialer Richtung eine stärkere sein, als in sagittaler, so daß eine Radiusverkürzung resul- 
Die physiologische Tragweite der dorsoventralen Linsenabplattung ist insofern vorläufig nicht abzuschätzen, als uns die Linsenradien der verschiedenen Altersstufen, von der Geburt bis zum Senium, unbekannt sind. Doch wird notwendigerweise die Abplattung eine Abnahme des Gesamtindex der Linse und damit eine Änderung der Refraktion des Auges zur Folge haben müssen. Da nun aber die mittlere Refraktion des Auges bei den meisten Individnen vom mittleren Kindesalter an bis ins höhere Alter völlig oder annähernd völlig stationär bleibt, bei ebenfalls stationärer Hornhautrefraktion, so folgt, daß die erwähnte, durch die Formänderung der Linse gegebene Herabsetzung des Brechungsindex in irgendeiner Weise kompensiert wird. Diese Kompensation geschieht wohl in der Hauptsache auf zweierlei Art. Bis zum Abschlusse des Wachstumes in erster Linie durch die Bulbusverlängerung, später vielleicht durch die Kernsklerose. Die Bulbuslänge beträgt beim Neugeborenen etwa 16, beim Erwachsenen etwa $24 \mathrm{~mm}$. Der Krümmungsradius der Hornhaut wächst, soweit Befunde vorliegen, bei weitem nicht in dem Maße, um die aus jener Verlängerung sich ergebende Refraktionsdifferenz auszugleichen, so daß wohl die Abplattung der Linse das Refraktionsgleichgewicht herstellen hilft.

Die Kernsklerose wiederum bedingt nach den vorliegenden Indexmessungen wahrscheinlich eine im Laufe des Lebens, wenigstens zeitweise, fortschreitende Steigerung des Gesamtindex, welche vielleicht wiederum durch die Abplattung ausgeglichen wird. Die Sklerose wäre dabei wieder der primäre, aus der Wachstumseigentümlichkeit der Linse (s. o.) sich erklärende Vorgang. Die Mögliohkeit einer derartigen Wechselbeziehung wird auch dadurch nahe gelegt, daß beide Prozesse, Sklerose und Abplattung, soweit bis jetzt übersehbar, das ganze Leben hindurch nebeneinander fortschreiten 1 ).

tieren würde. Eine solche Schrumpfung müßte aber anch eine Radiusverkürzung der Linsenoberfläche (Vorder- und Hinterfläche) nach sich ziehen, so daß diese Hypothese mit den Tatsachen in Widerspruch stände. Doch ist einstweilen nicht untersucht, ob nicht neben der Abflachung, auch noch eine derartige Krümmungszunahme der schrumpfenden Kernpartien besteht und zur Erhöhung der Divergenz beiträgt.

1) Die starke Hypermetropie, welche durchschnittlich das Neugeborenenauge auszeichnet, scheint in den ersten Lebensjahren durch das Längenwachstum des Bulbus ausgeglichen zu werden, das nach den Untersuchungen von Weiss (Ber. Heidelb. 1895) besonders lebhaft zwischen 1. und 3. Jahr stattfindet. Dieser angeborenen Hypermetropie steht die sog. Altershypermetropie gegenüber, die, soweit sie nicht einfach manifest gewordene Achsenhypermetropie ist, zum Teil auf Linsenabplattung, zum Teil auf senile Miosis (Gullstrand) bezogen wurde. Daß anch eine die Rinde ergreifende Indexerhöhung den Gesamtindex herabsetzen müBte, hat zuerst Thomos Young bewiesen. Docb sprechen die Indexmessungen Freytogs (die allerdings an kleinem Material angestellt sind) gegen eine derartige senile Indexänderung dex Rinde. Die im Alter häufig (aber 


\section{Abnahme der Linsendicke durch Trauma.}

\section{(Posttraumatische Linsenatrophie.)}

Nach schweren Kontusionen oder Perforationen, die zu Linsenschädigung führten, kann die Spaltlampe eine Verdünnung der Linse in sagittaler Richtung erkennen lassen.

Ein solcher Fall ist der bereits erwähnte in Abb. 14 wiedergegebene. Der dortige Linsenbefund sei in folgender Weise ergänzt: Das Spaltlampenbüschel zeigt eine (auf keinem anderen Wege erkennbare) sagittale Linsenverdünnung. Beim Blick geradeaus und bei Einfallswinkel von $40^{\circ}$ (Messung mit unserem Spaltlampenwinkelmesser) ergibt die Beobachtung mit dem Okularmikrometer die Vergleichszahlen rechts 20 , links 32 (Mikrometer für beide Messungen im medialen Okular, temporale Lampenstellung). Es verhält sich also die Dicke der rechten zu der der linken Linse ungefähr wie $2: 3$ (Abb. 27, als Hinterfläche galt die Zone P).

Bemerkenswert ist im vorliegenden Falle das genauere Verhalten der vorderen Diskontinuitätszonen (Abb. 27

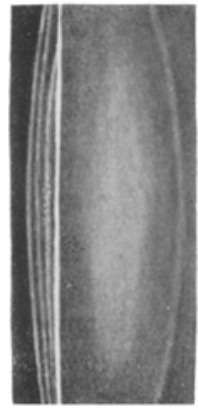

Abb. 27. und $\mathrm{Abb} .28$ ). Wir erblicken in der (durch Apposition neugebildeten) Vorderrinde vier solcher Zonen, welche alle einen mehr oder weniger unregelmäBigen Verlauf nehmen.

1. Die Kapselzone, welche fleckweise getrübt ist, die Trübungen erscheinen vereinzelt chagrinlos (Abb. 28, Zone 1). Die Kapselzone erscheint von geringerer Wölbung als normal.

2. und 3. Eine zweite und dritte, jedoch nicht überall sicher nachweisbare, oft von leichten Trübungen oder optisch leeren (dunklen) Stellen unterbrochene Zone (Abb. 28, Zone 2 und 3).

4. Die lichtschwache vierte Zone (Alterskernzone? Abb. 28, Zone 4), welche sich durch größte Flachheit und durch besondere Lichtstärke zufolge flächenhaft ausgedehnter Trübungen auszeichnet. Diese Zone liegt iuberall in ein und derselben Ebene, erst in der Nähe des auf $8 \mathrm{~mm}$ erweiterten Pupillenrandes beginnt eine fast plötzliche Abbiegung nach hinten, dem Äquator zu.

Es ergibt sich aus dem geschilderten Verhalten der vorderen Diskontinuitütsstreifen ohne weiteres, daß sie nach der Peripherie hin gegeneinander konvergieren (Abb. 27, 28).

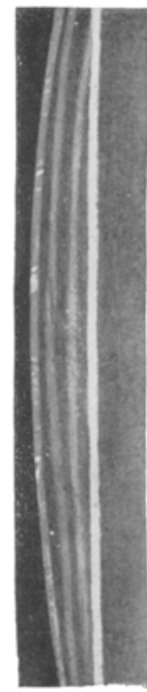

1234

Abb. 28.

nicht konstant!) zu beobachtende Kammerabflachung ist in ihrer Ursache nicht abgeklärt. Mehrfach wurde sie als Ausdruck eines Nachvornerückens der Linse gedeutet. Diese Lageänderung würde eine entsprechende Verschiebung des hinteren Brennpunktes nach vorn zur Folge haben. Vielleicht kommt aber die Abflachung durch eine Linsenverdickung zustande. Spaltlampenuntersuchungen in dieser Richtung wurden noch nicht angestellt. 
Und zwar geht die Konvergenz so weit, daß der dritte Streifen mit dem vierten unmittelbar verschmilzt (Abb. 28, oben), während der erste und vierte sich einander hochgradig nähern. Diese periphere Konvergenz der Diskontinuitätszonen ist als pathologisch zu bezeichnen und steht im vorliegenden Falle wahrscheinlich mit den Störungen, welche zu der Reduktion des Linsenvolumens geführt haben, im Zusammenhang. Normalerweise divergieren, wie wir oben geschildert haben, die Diskontinuitätszonen nach der Peripherie hin sehr beträchtlich.

An die vierte Zone schließt sich eine diffuse Kerntrübung an, welche die Beobachtung feinerer Einzelheiten im hinteren Abschnitt unsicher macht. Doch tritt in dieser Gegend ein intensiv weißgelber Streifen hervor $(\mathrm{Abb} .27 \mathrm{P})$ von dem es aber nicht feststeht, ob er der Hinterkapsel zugehört oder nicht. Dieser Streifen zeigt eine ähnlich starke Wölbung wie derjenige der Vorderkapsel.

Wir haben es im vorliegenden Fall mit einer bedeutenden Volumverminderung der Linse nach Contusio bulbi zu tun, die wohl in ähnlichen Fällen bisher deshalb unbekannt bleiben mußte, weil vor der Erfindung der Gullstrandschen Spaltlampe eine Methode zu ihrem Nachweise fehlte. Die Ursache dieser Volumverminderung ist an. scheinend in der Resorption getrübter Linsenpartien, eventuell im Austritt solcher, vielleicht auch in Wachstumsstörungen zu suchen, die durch Epithelzertrümmerung bedingt sein könnten. Sie haben im vorliegenden Falle nicht nur eine sagittale Verdünnung, sondern auch eine Applanation der Linse zur Folge gehabt, die insbesondere in der völlig planen traumatischen Trübungsfläche (Zone 4, Abb. 28) zum Ausdruck kommt. Kapselfaltungen, wie sie etwa eine Schrumpfung hervorrufen müßte, sind nicht nachzuweisen. Auch ein Kapselri $\beta$ ist nirgends zu sehen.

In bezug auf das Zustandekommen der peripheren Konvergenz vorderer Diskontinuitätsflächen sind wir einstweilen auf Vermutungen angewiesen; doch ist anzunehmen, daß diese Veränderung mit der hier nachgewiesenen posttraumatischen Linsenatrophie in direktem $\mathrm{Zu}$ sammenhange steht. Ein Ausdruek derselben ist die Abflachung der vorderen Kataraktschicht (Abb. 28, Zone 4), welche wohl zur Entstehung der Konvergenz wesentlich beiträgt.

Daß ähnliche Bilder auch durch traumatischen Austritt von Linsensubstanz zustandekommen können, lehrt Abb. 29, welche die rechte Linse der 23 jährigen Frl. Meier 2 Monate nach einem perforativen Trauma zeigt. Durch das Trauma (Anschlagen an ein Ofentürchen) war der nasal untere Limbus durchbohrt, Uvea, Glaskörper traten in breiter Ausdehnung vor, so daß eine Corneoscleralnaht angelegt werden mußte. Die äquatorial verletzte Linse trübte sich vollständig, und war 6 Wochen später sagittal auf die Hälfte ihrer Dicke verdünnt, wie der Vergleich mit dem anderen Auge ergab. Die Verdünnung war am stärksten in der Höhe der Perforationsstelle (Abb. 29a und b). Hier saßen unter der Kapsel 
unregelmäßige Flüssigkeitsansammlungen in Wasserspaltenform (Abb. 29 b). In dem mittleren und temporalen Abschnitt ließen sich trotz der Trübung die vorderen und hinteren Diskontinuitätszonen noch deutlich unterscheiden (Abb. $29 \mathrm{c}, \mathrm{K}=$ Cornea, $\mathrm{A}=$ Vorderkapsel, $\mathrm{P}=$ Hinterkapsel, unter A und $\mathrm{P}$ die Diskontinuitätazonen).

Ein Jahr post trauma ähnliches Bild, doch hatte die Verdünnung etwas zugenommen. Lucide Substanz hatte sich nieht apponiert. Später starke Vorderkapselfaltung, unter weiterer Verdünnung der Starschicht; $\mathrm{R} \mathbf{S}=$ Finger in $1 \frac{1}{2} \mathrm{~m}$.

Dieser Fall lehrt, daß bei ausgedehnter, die ganze Linse betreffender Schädigung eine Apposition junger lucider Substanz ausbleibt.

In anderen Fällen ist diese Apposition mehr oder weniger stark beeinträchtigt.

So wurde im Falle der Abb. 277 (Atl. d. Splm.) im Laufe von 10 Jahren nur eine recht dünne Schicht neuer Substanz angesetzt, wohl entsprechend der ausgedehnten Gesamtschädigung der Linse (Rinden- und

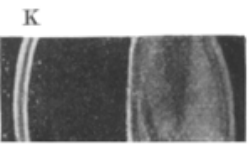

Abb. $29 \mathrm{a}$

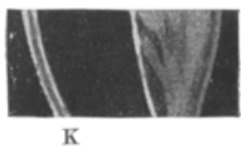

Abb. 29 b.

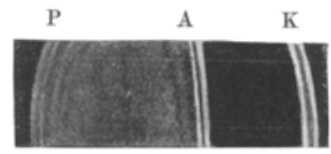

Abb. $29 \mathrm{c}$. Kernkatarakt).

Ahnliches gilt für den Fall Pf., Abb. 14 und 27 vorliegender Mitteilung.

\section{Sagittale Linsenverdiekung bei Glaukom.}

In Abb.9le des Atl. d. Splm. bildete ich einen Fall von ungewöhnlicher Linsendicke bei einer 70 jährigen Frau mit durch Iridektomie geheiltem chronischem. Glaukom ab. Dieselbe Beobachtung machte ich seither in zwei anderen Fällen, die ebenfalls Glaukom betrafen. In dem ersteren dieser beiden Fälle (72 jährige Frau Ha. K. mit Glaucoma absolutum rechts, hatte die Linse ein ähnliches Aussehen, wie im Falle der zitierten Abb.91c. Die Verdickung fand anscheinend hauptsächlich auf Kosten der Rinde statt. Der Kern zeigte auch hier etwas vermehrte innere Reflexion.

Eine Messung der Verdickung wurde im dritten Falle versucht: Die 49 jährige Frau M. Wa. leidet seit Jahren an beidseitigem Glaucoma secundarium zufolge chronischer Iridocyclitis. Linke Linse wegen Pupillenverwachsung nicht genauer untersuchbar. Rechts wurde vor 11 Jahren die Iridektomie nach oben ausgeführt. Die Linse zeigt an der Spaltlampe schon makroskopisch eine ungewöhnliche sagittale Dicke. Der Vergleich mit gesunden Augen (Messung bei gleichem Winkel zwischen Einfalls- und Beobachterriohtung) ergibt ein Verhältnis der Linsendicke des vorliegenden Falles zur normalen etwa von $15: 11$, d. h. die Linse ist um nahezu $1 / 3$ des Normalwertes verdickt. Sie zeigt zahlreiche Diskontinuitätsflächen, alle von auffallend unscharfer Begrenzung. Am hinteren Pol beginnende Cataracta complicata, in Form weißer wolkiger Trübungen. R S $=6 / 18$ Glbn. Tension $\mathrm{R}=17(\mathrm{~L}=13)$.

$\mathrm{Ob}$ die Volumenvergrößerung der Linse bei den erwähnten Glaukomfällen primär oder sekundär auftrat, ließ sich nicht entscheiden.

Weitere Beobachtungen über Cataracta complicata anterior (Abb. 30, 31). Cataracta complicata anterior bei Neurodermitis disseminata (Abb. 32).

Cataracta complicata beobachtete ich in seltenen Fallen bei degenerativer Myopie. Es kann hierbei sowohl die vordere als die hintere 
Rinde betroffen sein. Viel häufiger und intensiver allerdings ist die Cataracta complicata anterior bei gleichzeitiger Netzhautablösung. Eine Trübung dieser Art gibt Abb. 30 wieder.

Die 64jährige Frl. B. hat rechts periphere vordere und hintere Rindentrübungen. Glaskörper mit Trübungsfetzen. Fundus myopicus, ausgedehnter unregelmäßiger zirkulärer Bügel, Pigmentverstreuung der Maculagegend. Fundusperipherie und Gesichtsfeld normal. $\mathrm{RS}=6 / 36$ mit $-20,0 \mathrm{D}, \mathrm{LS}=1$. Links unsichere Projektion, vordere und hintere Cataracta complicata, Amotio retinae 1912 zum erstenmal beobachtet. Papillenrefralstion $-20,0 \mathrm{D}$. Die vordere Rindentrübung des linken Auges (Abb.30) zeigt eine Form, wie wir sie ähnlich bei Altersstar niemals antreffen. Man beachte die Beschränkung hauptsächlich

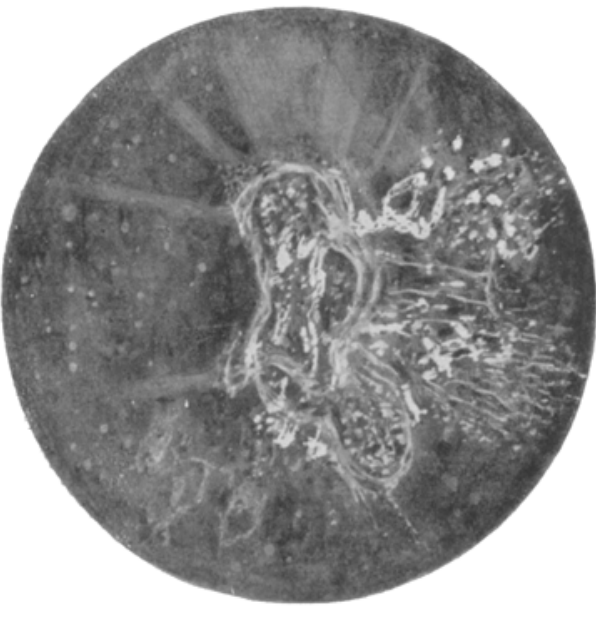

Abb. 30. auf die axialen Partien, während die Peripherie - im Gegensatz zum Altersstar - fast völlig freibleibt. Bezeichnend ist ferner die Ringbis Girlandenform der Trübungen, die zu einem merlswürdigen Gesamtbilde Anlaß gibt, wie wir es ebenfalls nie bei Altersstar finden. Man könnte von einer Cataracta annularis sprechen. Daß derartige Ringbildungen oft ans Flüssigkeitsansammlungen hervorgehen, deren Ränder sie bilden, konnte ich mehrfach nachweisen (vgl. Verf. Atl. d. Splm. Text zu Abb. 272, 276). Auch im vorliegenden Falle zeigt das schmale Bưschel fast völlige optische Leere der Partien innerhalb der Trübungsringe, wobei ohne weiteres erkennbar ist, dab die Flussigkeitsansammlung nicht nur in ihrer äquatorialen Zirkumferenz, sondern überall, auch vorn und hinten, von trïber Substanz umhüllt wird. Diese Hülle zeigt stellenweise Faserzeichnung. In den peripheren Partien der Katarakt treten unregelmäßige Radiärstreifungen, der Faserrichtung entsprechend, hervor. Auch in diesem Falle finden sich jene porösen, tuffsteinähnlichen Wölkchentrübungen, die die Cataracta complicata auszeichnen.

Während beim Altersstar die Flüssigkeitsansammlungen vorwiegend in der Naht- und Faserrichtung stattinden und dort zu Wasserspalten, Speichen- und Flächentrübungen führen, ist die Cataracta complicata, besonders die vordere, häufig durch die oben geschilderten, rundlich begrenzten Flüssigkeitsansammlungen ausgezeichnet, die zu runden Ringtrübungen Anlaß geben. Die Cataract blieb im vorliegenden Falle seic der ersten Beobachtung vor anderthalb Jahren bis heute stationär.

Die von uns schon früher nachgewiesene (Verf. Kl. M. f. A. 62, 593, 1919, vgl. auch Text zu Abb. 271 des Atl. d. Splm.) Bevorzugung 
der Diskontinuitätszonen bei Ausbreitung der Cataracta complicata posterior fand ich gelegentlich auch in der vorderen Rinde.

Abb. 31 zeigt den vorderen komplizierten Polstar bei dem 31 jährigen Al. mit Retinitis pigmentosa. Die aus weißen Wölkchen und unregelmäßigen weißen Streifen bestehende, allmählich in der Umgebung sich verlierende Trübung liegt zum Teil subkapsulär, zum Teil dagegen breitet sie sich flächenhaft im Bereiche der ersten Discontinuitätszone aus, welehe, wie Abb. 31 lehrt, ihre Lage etwas vor der Mitte, zwischen Kapsel und Alterskernzone, hat.

Rasch fortschreitende komplizierte Stare führen bekanntlich nicht nur frühzeitig zu Kapselschrumpfung, sondern auch häufig zu ausgebreiteten vorderen Kapselstaren. Diese zeigen häufig an ihren Rändern eigentümlich konkavbogenförmige Begrenzung (Abb.32).

Der 28 jährige robuste E. K. leidet seit frühester Jugend an ,disseminierter Neurodermitis" [Diagnose der hiesigen der-

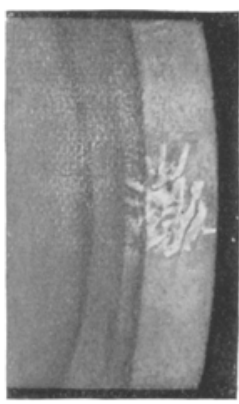

$\mathrm{Abb} .31$. matologischen Klinik, Vorstand Prof. F. Lewandowsky $\left.\left.{ }^{1}\right)\right]$. Lidhaut und Stirnhaut elephantiastiseh verdickt, mit Borken und Kratzeffekten. Sah früher stets gut, war Schütze. Familiär keine Sehstörungen. Links seit $1 / 2$ Jahr Visus schlechter. Heute weißblaue Milchkatarakt links, ausgedehnter vorderer Kapselstar im axialen Gebiet, vertikal 3, horizontal 3,5 mm messend (Abb. 32), Am Kapselstarrande typisches Verhalten des Chagrins. Letzterer ist uber dem Star lickenhaft, farbenschillernd. Man beachte die bogige Begrenzung des Stars! In der Umgebung einige isolierte Kapselstarflecken.

Am andern (rechten) Auge ebenfalls Cataracta complicata (incipiens). Dabei ist beachtenswert, daß die bei Durchleuchtung rosettenförmige Trübung anscheinend ausschließlich die vordere Rinde betrifft. Die Strahlen der Rosette treten nur schwach hervor. Charakteristische Trübungswolken, die zum Teil subkapsulär liegen, folgen vornehmlich der Nahtrichtung und sind axial besonders stark ausgesprochen. Da und dort ist Faserzeichnung zu sehen. Der vordere Chagrin hat an den Stellen dichterer

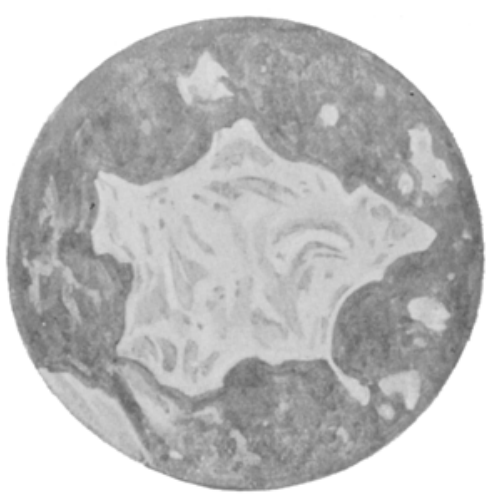

Abb, 82 Triibung seine Struktur verloren und zeigt überall kräftiges Farbenschillern. Hintere Rinde nicht sehr gut übersehbar, soweit erkennbar, ist sie jedoch trübungsfrei. Glaskörpergerüst destruiert, mit braunroten zahlreichen Punkteinlagerungen (diese kommen auch am linken Auge nach der Extraktion zum.

J) Lewandowsky stellte den Fall am 29. XI. 1917 in der Med. Ges. Basel vor. Damals bestanden noch keine Sehstörungen (vgl. Korr.-Blatt f. Schweizer Ärzte, 1918, Nr. 29). Das Krankheitsbild der Neurodermitis disseminata wird, wie Lewandowsky bemerkt, auch heute noch häufig mit dem des chronischen Ekzems verwechselt. 
Vorschein). Im rotfreien Licht fehlt der Maculareflex, und es besteht Andcutung radiärstehender präretinaler Reflexlinien. $\mathrm{RS}=\operatorname{schwach} 6 / 18(\mathrm{H} 1,5), \mathrm{LS}=$ Finger in $50 \mathrm{~cm}$ (Visusabnahme rechts seit einigen Wochen).

Nach der Linearextraktion links schwarze Pupille, LS $=6 / 6(+11,0=+$ cyl. 1,5 Achse $\left.60^{\circ}\right)$. Ophth. normal.

Drei Monate später bietet die rechtsseitige Katarakt insofern ein neues Bild, als vorn axial im Zentrum der Rosette nun auch ein ganz ähnlicher, eckig-ovaler Kapselstar aufgetreten ist, wie er links bestand. Maße 2:3 mm. Er zeigt, wie die Umgebung, Farbenschillern. Der für Kapselstar typische chagrinfreie Saum ist vorhanden. Die hintere Rinde weist nun, besonders axial, ebenfalls wölkchenförmige beginnende Trübungen auf.

Offenbar steht im vorliegenden Fall der Star im Zusammenhang mit der Dermitis. Die bogige Begrenzung des Kapselstares besitzt vielleicht zu der Radiäranordnung der Nähte Beziehungen. (Vgl. auch eine ähnliche Beobachtung im Atl. d. Splm. Abb. 184, ferner Klin. M. f. A. 59, 518, 1917). Beachtenswert sind die beidseits vorhandenen Veränderungen des Glaskörpers, und die frühzeitige Kapselstarbildung.

Diese außergewöhnliche Form der Cataracta complicata bietet auch allgemeines Interesse. Denn es läßt sich zeigen, daß ihre Struktur mit dem Grundleiden Beziehungen besitzt. In vier ähnlichen Fällen nämlich, die Andogsky mitteilt (K]. M. f. A. 52. Bd. 1914) und die alle bei chronisch entzündlichen Hautaffektionen jugendlicher Personen auftraten ${ }^{1}$ ), begann die Katarakt ebenfalls, wie in unserem Falle, als vordere subkapsuläre Rosettentrübung (Andogsky spricht von .,Cataracta stellata anterior"). Es kann somit keinem Zweifel unterliegen, daB die ungewöhnliche Form in Andogskys und in unseren Fällen der Ausdruck des besonderen Grundleidens, der chronisch entzündlichen Hauterkrankung ist.

Von Rothmund ist vor 54 Jahren (Arch. O. G. 14, 159, 1868) ein anderer Typus der „Cataracta dermatogenes", wie sie Andogsky nennt, beschrieben worden: nämlich eine ausgesprochen familäre Form. Fand sie sich doch in drei Familien mit 14 Kindern fünf- bzw. siebonmal. Die Eltern waren verschont. Heute, nachdem die Mendelschen Gesetze bekannt sind, darf die Rothmundsche Starform als recessive bezeichnet werden, und es wäre von Interesse, den Deszendenten der betreffen. den Familien, soweit sie nicht ausgemerzt sind, nachzuforschen. Die Stammbäume, die sich aus den leider in bezug auf die Aszendenz mangelhaften Notizen Rothmunds konstruieren lassen, seien hier ihrer theoretischen Bedeutung wegen wiedergegeben:

1) Prof. Lutz, Vorstand der hiesigen dermatologischen Flinik, hatte die Freundlichkeit, die von Andogsky mitgeteilten Krankengeschichten nachzusehen, und ist der Ansicht, daß es sich in Fall 2-4 Andogskys mit Wahrscheinlichkeit ebenfalls um Neurodermitis disseminata gehandelt hat. 


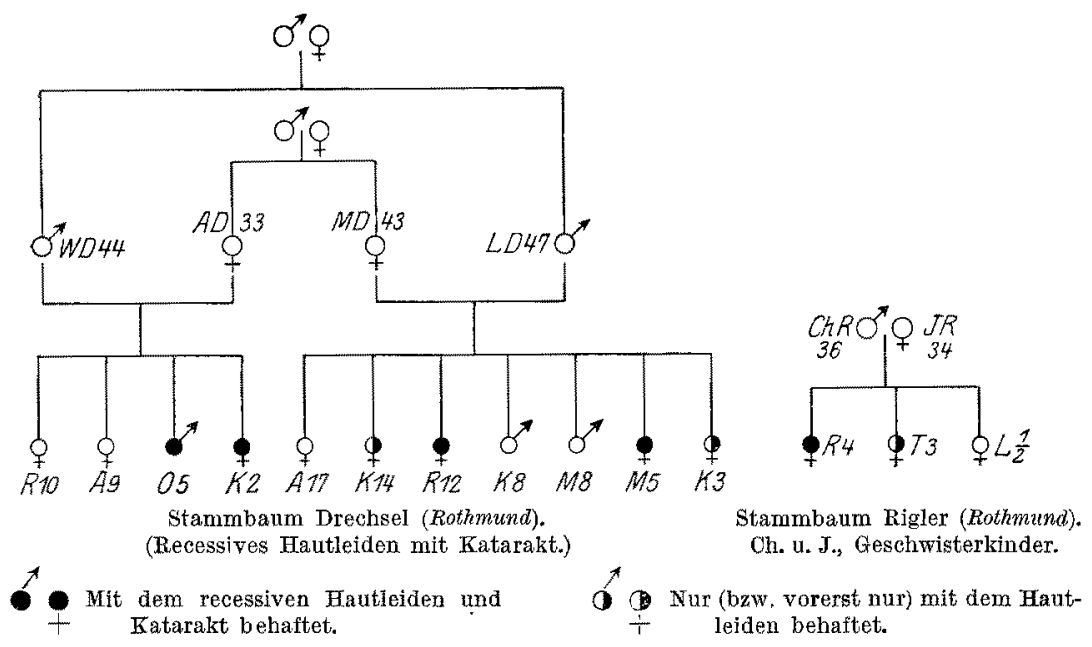

Der recessive Charakter der Krankheit kommt in diesen Stammbäumen nicht nur durch das Verschontbleiben der Ascendenz, sondern auch durch die Bedeutung der Verwandtenehe zum Ausdruck. Die Vererbung geschieht nach der Formel $\mathrm{Dd} \times \mathrm{Dd}=\mathrm{DD}+2 \mathrm{Dd}+\mathrm{dd}$, wobei $\mathrm{D}=$ gesundes Merkmal dominiert über $\mathrm{d}=$ pathologisches Merk. mal. $(\mathrm{DD}=$ normal, $\mathrm{Dd}=$ latent affiziert, $\mathrm{dd}=$ manifest affiziert.)

Der Rothmundsche Star trat akuter auf als derjenige Andogskys: In wenigen Tagen bildete sich nach Beginn der Trübungen Vollstar (gewöhnlich zwischen dem 2. und 6. Jahre), während in Andogskys Fällen, wie in dem analogen unsrigen, bis zur Vollendung der Trübung Monate verflossen und der Star erst später, nach dem Kindesalter auftrat. In Rothmunds Fällen begannen die Trübungen anscheinend nicht axial, sondern in der vorderen peripheren Rinde, in Form spitzer Dreiecksstreifen. Immerhin wird auch hier der Beginn in der vorderen Rinde hervorgehoben.

Die früh auftretende Hauterkrankung war chronisch-entzündlicher Natur und führte zu einer fettigen (?) Degeneration und Atrophie des Stratum Malpighii ${ }^{1}$ ).

Nicht streng hierhergehörig ist wohl eine Beobachtung Niedens: Katarakt bei Teleangiektasie der Gesichtshaut, Beginn als hintere Rosette.

1) $\mathrm{Ob}$ die von Rothmand im Corium nachgewiesenen Tropfen wirklich Fett waren, ist nicht zu entscheiden. Wurden doch zu jenen Zeiten auch die Myelintröpfchen des Stars als Fett angesprochen. Kollege Lutz, der die Freundlichkeit hatte, die Rothmundsche Beschreibung nachzusehen, teilt mir mit, daB Neurodermitis mit Sicherheit nicht vorlag, daß aber eine bestimmte Diagnose sich heute nicht mehr stellen lasse. Es handelte sich anscheinend um einen entzündlichen, atrophisierenden und wohl auch sklerosierenden Prozeß, mit sekundärer Atrophie der Epidermis. 


\section{Zwischen mittlerem und hinterem Linsendrittel sich ausbreitende beidseitige} Kataraktschale bei überstandener Keratitis parenchymatosa (Abb. 33).

Die Rubrizierung dieser, bei einer 37 jährigen mit der Spaltlampe gefundenen Katarakt ist nicht leicht. Die myopische Pat. hat zweima: 1 , mit 10 und mit 16 Jahren. eine Keratitis parenchymatosa durchgemacht. Heute bis zur Descemeti reichende unregelmäBige Hornhautnarben und tiefe Gefäße. Der 70jährige Vatex der Pat. zeigt beidseitige ansgedehnte Chorioiditis aequatorialis inveterata. WaR. negativ.

Der Linsenbefund bei der Tochter ist in Abb. 33 wiedergegeben. Eine leb. haft weißgelbe bis rothellgelbe, nach rom konkave Trübungsschale c liegt beid-

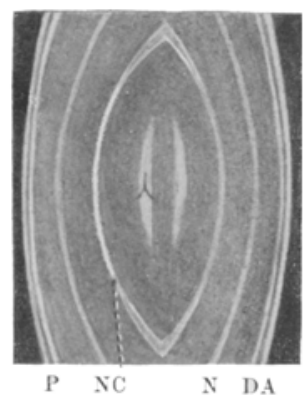

Abb. Bz: seits im axialen Gebiet, an der Grenze zwischen mittlerem und hinterem Linsendrittel. Die Schale nimmt die Lage einer Diskontinuitätszone, die sich um den zugehörigen Aquator herum in die vordere Linse vexfolgen läßt, ein. Diese Zone ist sowohl in der Äquatorialgegend als auch vorn trübungsfrei. Die Trübungsschale c erreicht, wie Abb. 33, linkes Auge (Sagittalschnitt), lehrt, den zuge. hörigen Aqualor an keiner Slelle. Am anderen (rechten) Auge sind die Verhältnisse fast genau übereinstimmend. Nur reicht hier die Trübung eher etwas näher an den Äquator heran.

Auffällig ist die relative Flachheit der Linsenhinterfläche (Abb. 33) und im Gegensatz hierzu die relativ starke Wolbung der Vorderfläche. In Abb. 33 ist $\mathrm{A}$ die Vorderkapselzone, $\mathrm{D}$ die Abspaltungs-, $\mathrm{N}$ die Alterskernzone, C die Kataraktzone und innerhalb derselben die Embryonalkernzone.

Ich führe diesen Fall im Anschluß an die Besprechung der Cataracta complicata an, weil man versucht sein kann, die Schalentrübung auf dieselbe Noxe zu beziehen, welche zur Keratitis parenchymatosa führte. Man könnte annehmen, daß die Trübung durch diese Noxe subkapsulär entstand und später durch Apposition gesunder Fasern in die Tiefe abgedrängt wurde. Gegen eine solche Annahme würde die tiefe Lage der Trübung sprechen (Abb. 33). Vielleicht führen andere, ähnliche Beobachtungen zur Auflklärung dieser Frage. Die Trübung ist auch insofern von Interesse, als sie mit den geläufigen Methoden (Lupenspiegeldurchleuchtung, seitliche Beleuchtung) nicht nachweisbar ist, eine auffallend gelbe bis rötlichgelbe Farbe aufweist und an beiden Augen mit abnormer Linsenwölbung einhergeht. Bemer. kenswerterweise fällt auch diese Trübung wieder in ihrer ganzen Ausdehnung in eine Diskontinuitätszone.

Seltene Form einer Cataracta complicata (Kupferstar?) (Abb. 34a-c).

An der außergewöhnlichen diagnostischen Bedeutung des von Purt. scher entdeckten Kupferstars kann kein Zweifel bestehen, wie das Z. B. wieder folgender Fall beweist, der an anderer Stelle ausführlicher mitgeteilt wird. Bei Herrn Kollegen Knüsel sah ich kürzlich einen Fall von ungewöhnlicher Funduserkrankung. Aus der Maculagegend, strahlte 
ein gelbroter Reflex, einer Lichtquelle vergleichbar. Es handelte sich um einen rundlich-eckigen metallisch, gelbrot glänzenden Fleck vom Durchmesser einer starken Vene. Fovealer Bezirk flach prominent, von einem. Kranze gelblichrötlicher Herde umgeben. Auffallend lebhafte gelblich-glänzende Gefäßreflexe. Es konnte die Diagnose Chalkosis retinae gestellt werden auf Grund eines typischen Sonnenblumenstars, der in charakteristischer, graumeergrüner Farbe dicht unter der Kapsel sich ausbreitete. Wieder, wie in dem von mir früher (Klin. Monatsbl. f. Augenheilk. 66. 1921) geschilderten Falle, lehrte das Spaltlampenmikroskop nich tnur den dicht subkapsu]ären Sitz, sondern auch die Zusammensetzung der Katarakt aus gleichmäßig feinen, eigentümlich glänzenden Pünktchen, die die ganze Linsenvorderfläche bedeckten und die Sonnenblumenfigur dadurch zustande kommen ließen, daß sie in deren Bereich wesentlich dichter standen $\left.{ }^{1}\right)$. Beginnende hintere, zum Teil auch vordere Cataracta complicata (wolkige, hauptsächlich axiale Trübungen und sublapsuläre Vakuolenansammlungen), äußerst lebhaftes Farbenschillern des vorderen und hinteren Spiegelbezirkes. Glaskörper mit eigentümlichen, an anderer Stelle genauer zu schildernder Veränderungen.

In diesem Falle war die Anamnese zunächst negativ. Der 22jährige Mann sah ohne erkennbare Ursache seit einigen Monaten an dem betroffenen Auge schlechter. Erst auf direktes Befragen nach einer stattgehabten Verletzung erinnerte sich Pat., daß ihm zwei Jahre früher im Militärdienst der Splittex einer Patrone gegen das Auge gespritzt war. Ein praktischer Arzt behandelte ihn einige Wochen, bis Reizlosigkeit auftrat. Das Röntgenbild (skelettfreie Aufnahme) zeigt heute den Splitter dicht hinter der Selera, $6 \mathrm{~mm}$ unterhalb unterm Limbus, nach Lokalisation mittels kleiner Angelhäkchen wurde der Splitter durch Meridionalschnitt ohne Glaskörperverlust entfernt. Nach Prof. Fichter besteht der Splitter aus Kupfer, Zinn oder Zink fehlte. Über die skelettfreie Aufnahme vgl. Schweiz. med. Woch. 1921, Nr. 7.

Der folgende Fall (Abb. 34 a, b, c) ist ätiologisch weniger klar. Doch erweckt die einzigartige Zeichnung und Farbe der Katarakt wenigstens den Verdacht auf einen (kryptogen) ins Auge gelangtenkupferhaltigen Splitter

Der 13 jährige Knabe W. F. hat angeblich links von jeher schlecht gesehen. Seit einigen Monaten erhielt er von einem Augenarzt Tropfen, und es versuchte letzterer eine Discision. Anamnese in bezug auf frühere Verletzung völlig negativ.

Hornhaut mit Discisionsnarbe. In der Nähe des unteren und nasalen Limbus sitzen im Bereiche des Endothels massenhafte, dichtstehende, feinste, grünschillemde Pünktchen. Diese Pünktchenzone ist etwa $2 \mathrm{~mm}$ breit und verliert sich allmählich in die Umagebung. Temporal und oben ist die Pünktchenzone weniger deutlich.

Von ungewöhnlicher Beschaffenheit ist die Katarakt. Abb. 34 a stellt das Oberflächenbild bei schwacher Vergrößerung dar. Man beachte den parazentralen dreieckigen Defekt, dessen Ränder gelbgrüne bis olivgrüne Farbe aufweisen. Er rührt von der Discision her, und es strahlen von ihm in radiärer Richtung zahlreiche

1) Die Pünktchen sind wohl die veränderten Epithelzellen (Verf. Klin. Monatsbl. f. Augenheilk. 66, 282). Die Strahlen der Starrosette entsprechen $m$. F. den Radiärfirsten der Irisrücklläche, in deren Bereich die Noxe auf die Linse stärker wirkt. 
grobe Kapselfalten aus. Abb. 34c zeigt diese Falten bei schwacher, Abb. $34 b$ (im Schnitt!) bei 37 facher Linearvergrößerung. Die Falten besitzen kräftige Faltenreflexe. Die Farbe der ganzen Linsenoberfläche ist ein eigentümliches. Grünlichblau bis Meergrün, wie ich es ähnlich nur bei Kupferkatarakt sah. Dieselben massenhaften, dichtstehenden, weiBgrauen Pünktchen ( $A b b .34 b$, vgl. auch Verf. Klin. Monatsbl. f. Augenheilk. 66, 269. 192l. Abb. 6), wie sie letztere Katarakt auszeichnen. liegen dicht subkapsulär. Eine Sonnenblumenfigur ist

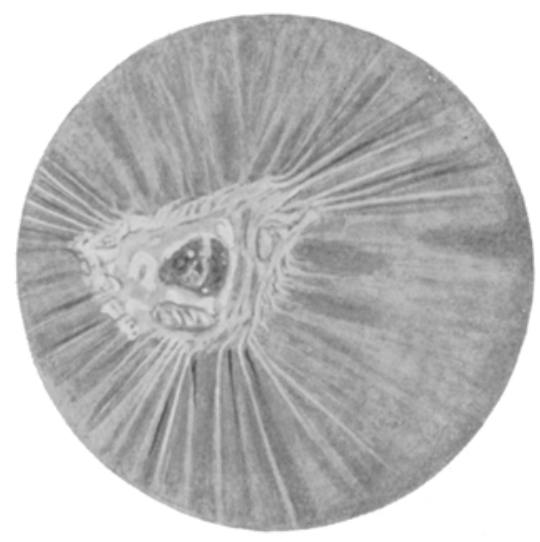

Abb. $3 \pm$ a.

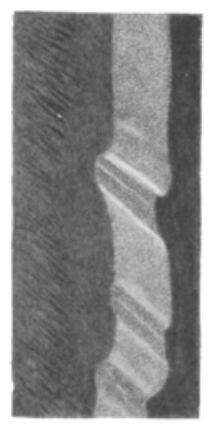

Abb. 34b.

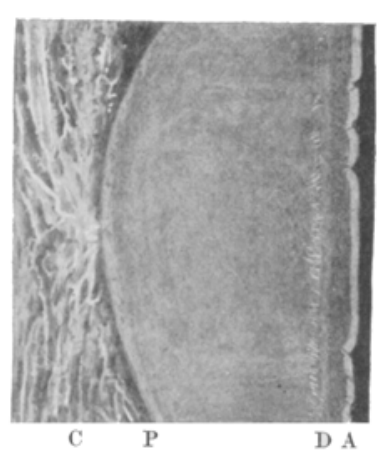

Abb. 34 e. nicht zu sehen und Farbenschillern fehlt. Der Sagittalschnitt (Abb. 34c) mit schmalem Büsehel lehrt, daß die Linsenvorderfläche A nicht normal gewölbt, sondern (wenn wir von den Einfaltungen absehen) vollkommen plan ist. In einigem Abstand von der Kapsel, von dieser durch relativ lucide Substanz getrennt, zieht zu ihr parallel die plane Diskontinuitätszone $\mathrm{D}$ hin, die dorsalwärts von einer Zone schräger gelber Parallelstreifchen gesäumt ist. Die nun folgende Linsensubstanz ist fein diffus getrübt, die Wölbung der Hinterfläche $\mathrm{P}$ kräftig. Dicht auf die Hinterfläche folgt das grau. gelbgrüne, intensiv getrübte, dichte Glaskörpernetzwerk c.

$\mathrm{LS}=$ Finger in $11 / 2 \mathrm{~m}$, Projektion vollständig, $\mathrm{R} S=6 / 6$. Mehrfache Röntgenaufnahmen negativ.

Mittels Kapselpinzette entfernte ich ein Kapselstück. Nach dem Vorderkammerschnitt entfeerte sich die Kammer nur teilweise, dafür sickerte eine sehr grobe Menge vollkommen wässeriger Glaskorperflüssigkeit heraus, wobei die linse etwas nach hinten sank. Nach einigen Tagen quollen trübe Linsenmassen in die vordere Kammer. In den folgenden Wochen spontane Resorption.

In dem in Formalin fixierten und in Paraffin eingebetteten extrahierten Stück erweist sich die Kapsel als intakt, stellenweise vielleicht etwas verdickt, das Epithel ist vielfach gewuchert, in spindlige Zellen verwandelt, die zum Teil gewöhnliches Kapselstargewebe bilden, zum Teil in einer homogenen Masse verstreut sind, welche von zahlreichen runden und ovalen Hohlräumen durchlöchert ist. Am Rande einzelner dieser Räume ist eine spindlig umgewandelte Epithelzelle nachzuweisen. Da, wo sich noch ein einfacher subkapsulärer Zellbelag nachweisen läßt, haben die Zellen stellenweise ebenfalls spindlige Form angenommen. Andere Partien weisen intaktes Epithel auf. Die anatomische Grundlage der feinen gleichmäBigen Punktierung lkonnte somit nicht ermittelt werden. 
Im vorliegenden Falle lassen die eigentümliche Zeichnung und Färbung der vorderen Subkapsulärzone, ferner wohl auch die grünliche Veränderung des Hornhautendothels, an intraokularen kupferhaltigen Splitter denken. Die Sonnenblumenfigur fehlt allerdings, ebenso wie das Farbenschillern, und das Röntgenbild ist negativ, so daß die Diagnose zweifelhaft bleibt. Daß eine komplizierte Katarakt vorliegt, beweisen die schweren Veränderungen des Glaskörpers: dichte, offenbar zusammengeballte, von gelbgrünen Auflagerungen bedeckte Gerüstmassen, unmittelbar hinter der Linse; ein Gerüst, von dem sich massenhafte wässerige Flüssigkeit losgeschieden hatte, welche sich bei der Eröffnung der Vorderkammer entleerte.

Präeipitate der hintern Linsenoberfläche (Abb. 35 und 36).

Diese schon von Gullstrand (37. Vers. O. G., Heidelberg 1911) in seiner klassischen Mitteilung über die Spaltlampe erwähnten Niederschläge sind von wechselnder Größe, meist rund, oft flüchtig. Thre Lokalisation ist mit schmalem Büschel möglich. Von Glaskörpereinlagerungen unterseheidet sie ohne weiteres ihre Bewegungslosigkeit. Sie nehmen hauptsächlich mittlere und untere Kapselpartien ein.

Abb. 35 zeigt diese Beschläge bei dem 22jährigen Dom., der seit einigen Monaten an Amotio retinae dextrae, anscheinend entzündlichen Ursprungs, leidet (25fache Vergrößerung). Zahlreiche Glaskörpertrübungen, Papille emmetrop.

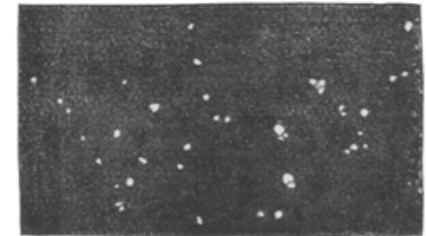

Abb. จิธ.

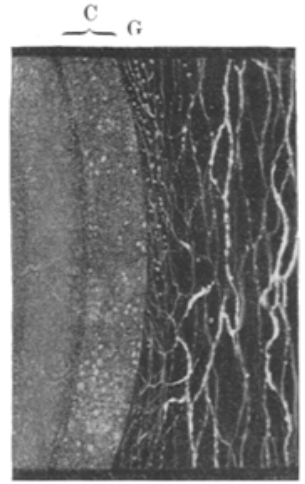

$\mathrm{Abb}, 36$.

Auch rein braune Pigmentpräcıpitate sind nicht selten. Sie können jahrelang stationär sein. Abb. 36 zeigt solche am rechten Auge des 58 jährigen A.M., mit beiderseitiger Amotio retinae, bei emmetroper Papille. Rechts hat sich die 1915 abgelöste Netzhaut wieder angelegt. $\mathrm{R} \mathrm{S}=$ Handbewegungen. $\mathrm{C}=$ Hinterkapsel mit Pigmentpräcipitaten, $G=$ corpusculäre Einlagerungen in das zerfallene, zum Teil verdichtete Glaskörpergerüst. Am linken Auge, mit seit 3 Monaten bestehender Ablösung, fehlen die Beschläge.

Weiterer Beitrag zur Kenntnis der dureh Vltrarot erzeugten Katarakt (Abb. 37, 38).

Über die Kataraktform vgl. Atl. d. Splm., Abb. 282-285 und 323 bis 328 . 
Die Bestrahiungen, die an unserer Klinik durch Herrn Dr. U. Lüssi fortgesetzt wurden, haben seit unsern letzten Mitteilungen u. a. ergeben, daß Monate nach der Bestrahlung sich in einem Falle ein Fadennetz in der vorderen Kammer nachweisen lieB, das ohne sorgfältige Focussierung der Beobachtung leicht entging.

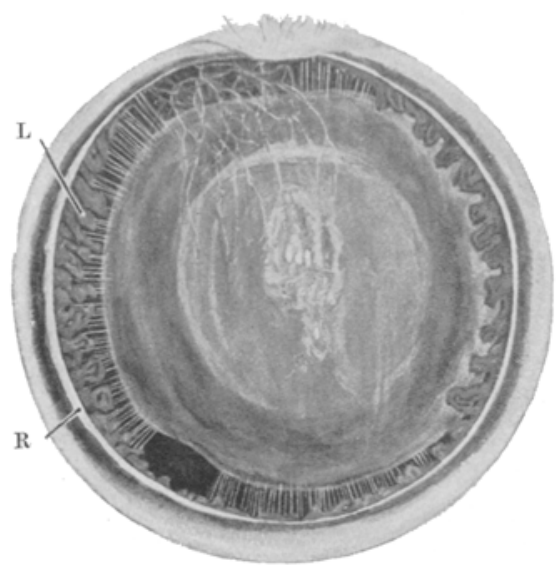

Abb. $3 \%$.

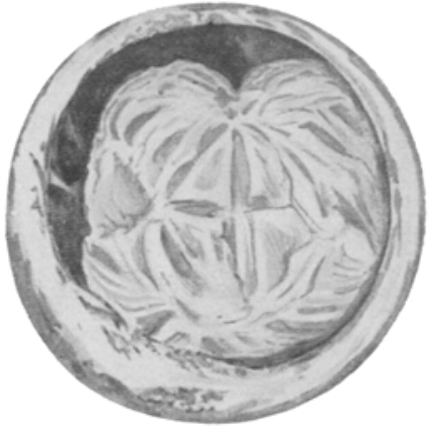

$\mathrm{Abb}, 38$.

Dieses Fadennetz ist in Abb. 37 dargestellt, welche ein Spätstadium des Falles Abb. 284 des Atl. d. Splm. darstellt (das Bild wurde ca. $21 / 2$ Jahre nach der Bestrahlung aufgenommen). Die Iris ist hochgradig atrophiert, zeigt immer noch den typischen weiBen Rand $R$ und stellt heute ein schmales peripheres Band dar. Die Fortsätze $\mathrm{C}$ des Corpus ciliare prominieren unregelmäßig (wir hatten diese Fortsätze, als sie eben über die Iris vorzuragen begannen, ursprünglich als Wucherungen des Irispigmentblattes aufgefaßt, vgl. Verf. Atl. d. Splm., Text zu Abb. 328). Linsenrand und Zonula sind fast überall sichtbar. Die Zonula fehlt an zwei Stellen, oben und unten. An diesen Stellen ist der Linsenrand flach eingekerbt.

Das genannte Fadennetz, das wir oben erblicken, stellt durch die Zonulalücke prominierendes Glaskörpergerüst dar. Über die anatomischen Befunde, welche $u$. a. hochgradige Irisatrophie und Schwund des Irispigments ergeben, wird später berichtet werden.

Die Linsertrübung, die ursprünglich subkapsulär lag, ist im Laufe der zwei Jahre stark in die Tiefe gerückt, ein experimentelles Beispiel für die Tiefenabdrängung trüber Substanz durch Apposition junger Fasern, gleichzeitig auch ein Beispiel für die Schrumpfung der zentralen Linsenpartien, vgl. Verf. Arch. f. O. G. 10\%, 214. In dem eben geschilderten Falle trat später Sekundärglaukom anf.

Abb. 38 zeigt die völlig geschrumpfte Katarakt des Falles Abb. 323 des Atl. d. Splm. Das weiße Band der atrophischen Iris ist wesentlich breiter als im vorigen Falle. Nach oben ist die Iris besonders stark verschmälert, die Ciliarfortsätze treten jedoch nirgends hervor. Zonulafasern sind nicht erkennbar. Aus den mittleren Teilen der geschrumpften Linse hebt sich scharf der kreuzförmig zerklüftete Kern $a b$, so daß ein Bild entsteht, das lebhaft an dasjenige macerierter Linsen erimnert. (Beobachtung ca. 11/2 Jahr nach der Bestrahlung. 5/4 Jahre später ähnlicher Befund, Linse noch weiter geschrumpft.) 